\title{
Los alcances de la inoculación y el impacto de la viruela de I797 en la parroquia de San Agustín Jonacatepec
}

\author{
The Scope of Inoculation Efforts and the Impact of Smallpox \\ on the Parish of San Agustín Jonacatepec in 1797
}

\author{
América Molina del Villar \\ Ciesas-Ciudad de México \\ avillar@ciesas.edu.mx \\ DOI: I0.2490I/rehs.v40i157.324
}

\section{(c) $($ ) (9)}

Los alcances de la inoculación y el impacto de la viruela de 1797 en la parroquia de San Agustín Jonacatepec por América Molina del Villarse distribuye bajo una Licencia Creative Commons Atribución-NoComercial 4.0 Internacional.

Fecha de recepción: 7 de julio de 2017

Fecha de aprobación: 28 de mayo de 2018

\section{RESUMEN:}

Este artículo examina el impacto de la epidemia de viruela de 1797 en una parroquia del centro novohispano, el curato de Jonacatepec, donde se enfermaron y murieron gran número de niños de entre 5 y 9 años. El brote de este año se extendió por gran parte de la Nueva España y del Imperio español. Es importante señalar que durante la epidemia se inoculó a gran número de personas. Las prácticas de inoculación -antecedente de la vacunación actual- tuvieron gran difusión y observamos que fueron exitosas porque cobró un menor número de víctimas. Lo anterior se comprueba en Jonacatepec, donde el dueño de dos haciendas envió a un médico a inocular a sus trabajadores. En el trabajo mostramos que en estas empresas la epidemia no fue tan severa en comparación con la cabecera pueblos, donde la población rechazó la inoculación. El estudio se apoya en documentos de archivo, padrones y un valioso padrón de enfermos y muertos, que fue elaborado durante la epidemia.

Palabras clave:

Viruela, inoculación, enfermos, haciendas, pueblos.

\section{ABSTRACT:}


This paper examines the impact of the smallpox epidemic of 1797 in Jonacatepec, a rural parish in Central New Spain, a severe outbreak that took the lives of many children below the age of 9. The study of this particular epidemic is important not only because the disease spread through broad areas of New Spain and the Spanish Empire, but also because efforts were made to inoculate the population. The procedure applied can be seen as an antecedent of current vaccination campaigns for it consisted in injecting pus from smallpox patients into healthy individuals who would thus contract only a mild form of this otherwise deadly disease. Inoculation was widely-diffused and, in the case of the outbreak of I797, achieved notable success because a smaller number of people died. This essay examines the situation in Jonacatepec, where the owner of two haciendas hired a doctor to inoculate his workers. The documental sources consulted show clearly that fewer people became sick or died on the haciendas than in the headtown and outlying villages, where people refused to be inoculated. Sources include archival documents, records and a valuable registry of patients and the dead, compiled during the epidemic.

Keywords:

Smallpox, inoculation, the ill, towns, haciendas.

\section{Introducción}

En el transcurso del siglo XVIII siguieron presentándose constantes brotes de viruela en la Nueva España. No obstante, a diferencia de los primeros siglos coloniales, la población había adquirido cierta inmunidad ante este padecimiento y para entonces había habido avances en la manera de frenar los contagios. Los brotes violentos de la enfermedad se presentaban cada diez años y solían afectar a la población infantil no inmunizada, aunque la inmunidad podía no ser permanente..$^{\perp}$ a desinfección, identificación de casos y aislamiento de enfermos fueron hasta el momento los únicos medios para frenar su diseminación y efectos mortíferos en la población. Para entonces, dos métodos cobraron gran importancia: la variolización (inoculación) y la vacuna. La primera se desarrolló probablemente en China y la India hace alrededor de dos mil años, aunque su práctica no fue generalizada y requirió más de un milenio para que se realizara en Europa. El método consistía en inocular costras de los enfermos a personas sanas, de brazo a brazo, o bien en la mucosa nasal. 2 A través de este método el paciente adquiría el virus y desarrollaba la enfermedad de manera atenuada. Sin embargo, este método podía presentar complicaciones y ser peligroso, pues se empleaban costras secas de enfermos con viruela. ${ }^{3}$ En I779 fue cuando por primera vez se llevó a cabo un programa de inoculación en la Nueva España, en el cual destacó la labor de Esteban Morel, científico francés. Morel por iniciativa del Ayuntamiento de la Ciudad de México elaboró una "Disertación" en torno a los beneficios de estas prácticas. ${ }^{4}$ El otro método para prevenir la viruela fue la vacunación, cuyo primer logro ocurrió en 1796 con el descubrimiento de Edward Jeneer, médico inglés, quien realizó los primeros experimentos vacunando a un niño de ocho años, James Phipps, utilizando linfa extraída de las vesículas del dedo de una ordeñadora llamada Sara Helmes. Después de algún tiempo se introdujo al niño la viruela humana y la enfermedad no evolucionó. Los primeros resultados de este experimento aparecieron en I79 8 bajo un ensayo titulado An Inquiry into the Causes and Effects of the Variolae Vaccinae. ${ }^{5}$ 
El descubrimiento de la vacuna de Jenner tardó algún tiempo en transmitirse a la Nueva España, aunque como ya referimos la variolización ya había adquirido amplia difusión. A lo largo de la década de i79o se publicaron diversos manuales sobre métodos para "practicar de manera clara, sencilla y fácil" la inoculación para prevenir la viruela. Empero, no todos los médicos estaban de acuerdo con sus beneficios y resultados. Otros textos cuestionaban este procedimiento y señalaban que el mejor método para evitar contagiarse era la "separación de los individuos". Así, $^{-}$ el 6 de agosto de I796, Francisco Gil, cirujano del real sitio y monasterio de San Lorenzo, ordenó reimprimir en la capital novohispana 200 ejemplares de la "Disertación sobre el método de preservar a los pueblos de viruelas", cuya primera edición al parecer fue de i785. El texto consta de 57 páginas y se indicaba que la separación de individuos y cuarentenas habían tenido gran éxito en la provincia de Lousiana. ${ }^{7}$ Sangrías, purgantes, utilización del mercurio, los baños, "opiados" eran algunos de los remedios alternativos y sugeridos en diversos manuales españoles reimpresos en la Nueva España en las décadas de i780 y г790. $\underline{8}$

En contraste, el Real Protomedicato sí fue partidario de los beneficios de la inoculación. En I797, este tribunal publicó un manual titulado: "Método claro, sencillo y fácil para practicar la inoculación de viruelas", acatando la disposición del virrey marqués de Branciforte. Se criticaba el uso de las sangrías y otras medicinas. En dicho texto se indicaba que las mejores personas para inocular eran los niños que "jamás hubiesen padecido las viruelas", o se "dude de haberlas tenido legítimas". Los propios padres sí así lo desearan podían inocularse. Los niños debían estar sanos, robustos, "no estén echando los dientes"; ni las niñas "con su regla o proximidad a ella". Unos ocho o quince días antes de la inoculación la persona debía abstenerse de consumir carne gruesa y salada, picante, bebidas ardientes, practicar ejercicios. Se recomendaba una buena alimentación con yerbas, frutas y semillas de bebidas refrescantes, como sueros, cocimientos de cebada, avena, agua vinagrada o limonada, tomar aire fresco en la mañana. ${ }^{2}$

Los manuales y tratados médicos en pro o en contra de la inoculación podrían obedecer a su todavía dudosa efectividad. El gobierno y ciertos sectores ilustrados fueron los principales promotores de los beneficios de la inoculación, cuestionando las viejas prácticas médicas como el uso de las sangrías y purgantes. De ahí el interés desde entonces de levantar registros y estadísticas de enfermos y muertos, iniciativa que en 1797 fue impulsada y ordenada por el propio virrey Branciforte a varias localidades y ciudades del virreinato afectadas por la viruela. A partir de estas estadísticas se intentaba difundir los beneficios de inocular a la población comprobando con datos duros la disminución en el número de muertes.

Cabe decir que los avances experimentales en el tratamiento contra la viruela ocurrieron en un momento de recrudecimiento de la enfermedad. Entre i790 y i798 se presentaron continuos y violentos brotes de viruela en varios dominios del Imperio. Es posible que estas manifestaciones sean un indicio de una gran pandemia: La Habana, Guatemala, Perú y la Nueva España padecieron los estragos de la enfermedad. - El contagio a la Nueva España parece que provino de Guatemala y de ahí se fue propagando a Oaxaca. Ante esta amenaza se pidió establecer cuarentenas, usar ropa blanca, instaurar hogueras para purificar el aire, así como sahumerios con azufre y al final se recomendaba llevar a cabo la inoculación. ${ }^{\text {II }}$ a subdelegación de 
Tehuantepec, frontera con la capitanía de Guatemala, fue la primera localidad del virreinato en donde se manifestó la viruela, al igual que en aplicar medidas preventivas, como la inoculación..$^{\underline{2}}$

Ante este contexto general, el interés en este artículo es analizar el impacto de la epidemia de viruela de 1797 en la parroquia de San Agustín Jonacatepec, en el actual Morelos. Nuestro objetivo es estudiar los efectos del padecimiento en la población y comparar su impacto entre la cabecera (donde se asentaba una población heterogénea compuesta por españoles, mulatos, mestizos), pueblos y las haciendas. Interesa confrontar indicadores demográficos de la mortalidad y letalidad entre niños y adultos, en el cual podemos adelantar que hubo una mortalidad diferencial entre estos grupos de edad, así como de acuerdo a su residencia y origen socioétnico. ${ }^{13}$ Otro eje del análisis es conocer la respuesta de las autoridades para enfrentar la epidemia, como fue la campaña de inoculación impulsada por Nicolás Icazbalceta, dueño de las haciendas de Tenango y Montefalco, quien también tuvo el cargo de teniente de justicia y personalmente "asistió a un gran número de enfermos, inoculando a más de 300 individuos". El hacendado costeó los gastos y envió al cirujano Rafael Atenza Palacio para inocular a sus esclavos. ${ }^{14}$

El estudio se sustenta en información diversa: informes, solicitudes de condonación de tributos, quejas, así como en un extenso y detallado padrón de enfermos y muertos por la viruela, elaborado por el cura de la feligresía y cuyo objetivo era registrar los nombres, origen socioétnico, edad y lugar de residencia de las personas que resultaron contagiadas, sanaron o murieron a consecuencia del brote de viruela de i797. Esta relación o "padrón general de los que han muerto y padecido la viruela" fue ordenado por el virrey Branciforte al subdelegado de Cuernavaca. ${ }^{15}$ Este documento es muy valioso y los datos permiten hacer diversos cálculos, como tasas de mortalidad y letalidad, en virtud de que podemos comparar el número de muertos y convalecientes por la viruela y hacer algunas aproximaciones de tasas de mortalidad a partir del total de población señalado en un padrón de eclesiástico de 1797 , fuente que registra el número de españoles, castas e indios de la parroquia de San Agustín Jonacatepec. Se presume que este padrón general de toda la feligresía fue levantado en abril durante la cuaresma, pues se trataba de un padrón de confesión. ${ }^{-6}$ A partir de los informes emitidos por las autoridades locales y del mismo registro de enfermos y muertos, podemos presumir que la viruela afectó a la parroquia de Jonacatepec a fines de septiembre de i797. En ese mes Cuatla Amilpas, cercana a este curato, ya se encontraba bajo los estragos de la enfermedad. ${ }^{17}$

El artículo se divide en tres partes. En el primer apartado presentamos un breve contexto histórico-regional del área estudio, para lo cual también hacemos referencia al impacto de otras epidemias y crisis que tuvieron repercusiones diversas en la población de Jonacatepec. En la segunda sección nos adentramos en la propagación de la viruela en la Nueva España entre i794 y 1798 , panorama que permite apreciar su gran expansión geográfica e impacto demográfico. En el tercer apartado describimos las acciones que emprendió el hacendado Icazbalceta en el momento de presentarse la epidemia, destacando su compromiso en las labores de inoculación de sus trabajadores. En esta parte presentamos algunas gráficas sobre el impacto diferencial de la viruela por grupos de edad, calidades y tipo de asentamiento en el curato de Jonacatepec.

Relaciones Estudios de Historia y Sociedad, vol. XL, núm 157, 2019 


\section{Contexto histórico-regional. Población y otras calamidades}

El curato de Jonacatepec se encontraba al poniente del actual estado de Morelos, en una zona en donde se desarrolló una importante agricultura comercial, principalmente de caña de azúcar y granos. Jonacatepec formaban parte de la llanura de Tlalnaguas y gozaba de tierras cálidas y templadas por debajo de los I,500 msnm. Durante la colonia en Jonacatepec, al igual que sus vecinas Cuautla y Yautepec, se desarrolló una importante industria azucarera que, a diferencia de otras regiones cañero-azucareras del Nuevo Mundo, siguió conservando un importante conglomerado de población indígena. Al parecer, Jonacatepec era una parroquia de menor envergadura económica en relación con los grandes productores de azúcar de Yautepec y Cuautla. $\frac{18}{-}$ En tanto en estas últimas localidades encontramos un gran número de haciendas y ranchos; en el área comprendida en el curato de Jonacatepec se identifican dos grandes haciendas: Santa Ana Tenango y Santa Clara Montefalco. 
Mapa I. Pueblos y haciendas del curato de Jonacatepec, I797

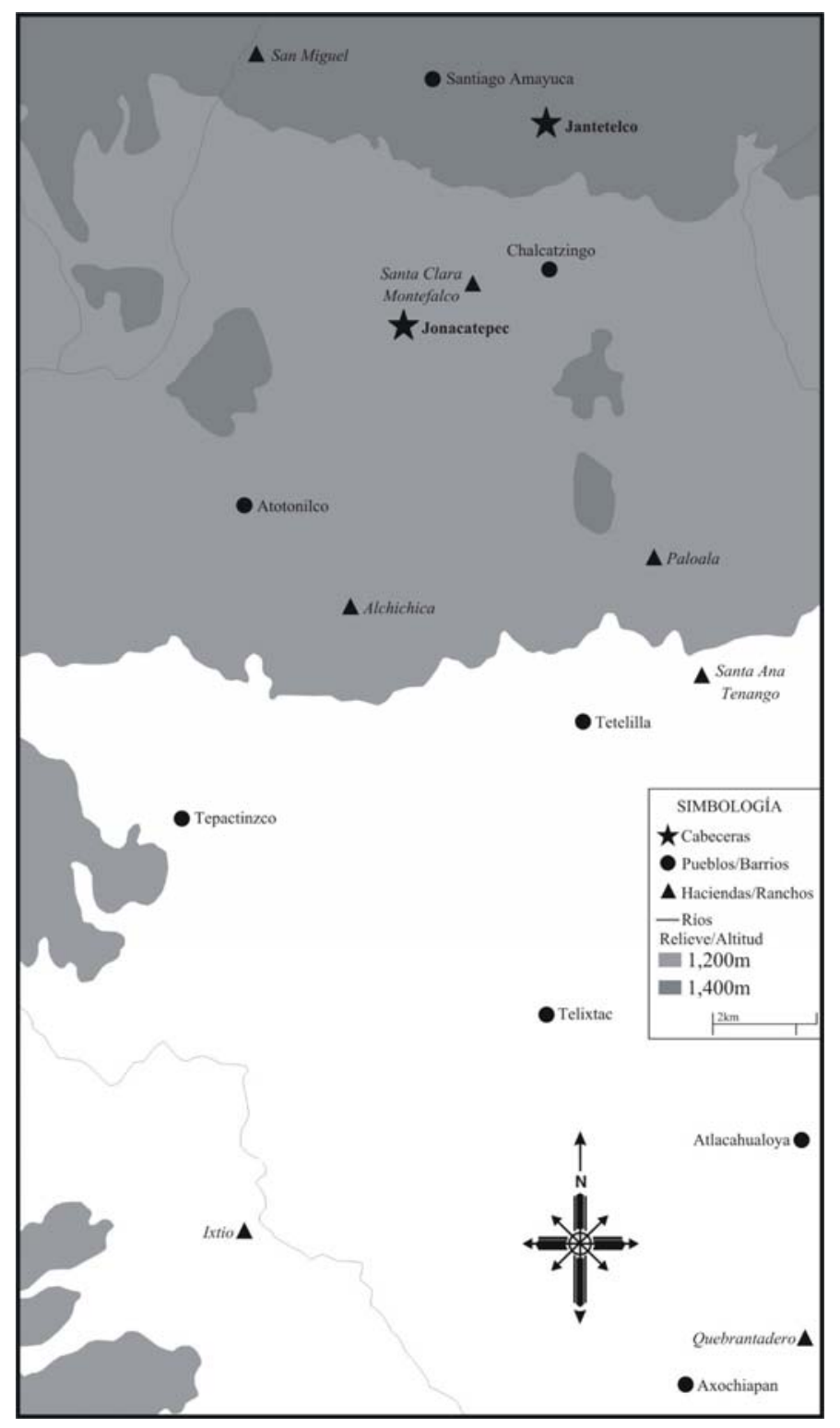

A diferencia de Cuautla y Yautepec, donde la crisis azucarera provocó que hubiera suficientes tierras a los habitantes de los pueblos, rancheros y aparceros, en Jonacatepec no había tierras y era un poco más árido, por lo que los indios fueron forzados a ganar el grueso de su subsistencia trabajando como asalariados en las haciendas. Como veremos más adelante, en las dos haciendas de este curato había una heterogénea población trabajadora conformada por esclavos, indios de cuadrilla y sirvientes "libres". Del mismo modo, gracias a los padrones sabemos que se registraron distintas calidades en los pueblos y haciendas, donde había familias de indios con mulatos y mestizos. ${ }^{19}$

Cabe referir que entre i69o y hasta i760 la población indígena de las regiones vecinas, en particular del altiplano norteño de las zonas azucareras emigró a las haciendas de las tierras 
bajas en busca de trabajo. Estos flujos de población aumentaron después de la epidemia de matlazahuatl de i737 y la subsecuente crisis agrícola de i740. Muchos de estos migrantes provenían de la alcaldía mayor de Chalco, lugar que mantuvo un fuerte intercambio comercial con Jonacatepec, primero por medio del agua para transportar azúcar y luego aguardiente a la Ciudad de México. ${ }^{20}$ Es posible que la presencia notable de indios, mulatos y mestizos en la cabecera y pueblos sujetos de Jonacatepec se deba a la llegada de estos inmigrantes a raíz de la epidemia de 1737 y de la crisis azucarera de los años sesenta. ${ }^{2 I}$ Este incremento de habitantes y de una heterogénea población se refleja en los datos de población que veremos a continuación.

A pesar de los indicios en torno al impacto de estas epidemias en el centro de México, la situación en el poniente del actual Morelos, donde se encontraba la parroquia de Jonacatepec, no es del todo clara, en virtud de que no disponemos de registros de entierros para conocer la curva de mortalidad. Sin embargo, en I76r y i762 volvieron a registrarse dos epidemias. A través de otro tipo de documentación sabemos que en i763 los indios dejaron de pagar tributos a consecuencia de una epidemia, la cual se extendió por las jurisdicciones de Toluca, Cuernavaca y Coyoacán..$^{22}$ El señor gobernador del estado y marquesado del Valle informaba que ya había cesado la epidemia, por lo que debía restablecerse el cobro de tributos, ramo importante para el pago de los curas y doctrineros. Los alcaldes mayores debían restablecer el cobro de tributos y realizar una nueva recuenta de tributarios. Sin embargo, un vecino de la villa de Cuernavaca informaba que en febrero de i763 todavía se padecían los estragos de la epidemia. ${ }^{23}$ El hecho de que se haya concedido la suspensión del pago de tributos revela que la población adulta resultó fuertemente mermada por la epidemia.

Así, observamos que tanto en I737 y I76r murieron muchos adultos, hecho que había perjudicado el pago de tributos. Los indios fueron las principales víctimas de estos trastornos, en virtud de que pese a las enfermedades y muertes debían cumplir con sus compromisos fiscales. La subsistencia de los indios dependía de su trabajo en las pequeñas parcelas. Sí muchos indios tuvieron que venderlas por rezagos del pago de tributos o bien por el embargo de sus bienes, no les quedaba más remedio que huir de sus pueblos y refugiarse en las haciendas e ingenios. Muchos indios fueron a residir a estas empresas con el objeto de subsistir. A pesar de estas crisis, entre I765 y i800, la población de los pueblos de indios de las 5i provincias del área central creció en un $52 \%$, lo que representó un promedio de $\mathrm{r} .5 \%$ anual. 24 Aunque para muchos lugares no podemos constatar este dato debido a que no hay uniformidad en las cifras, en el caso de Jonacatepec sí podemos comprobar que hubo un importante crecimiento entre i 768 y fines del siglo XVIII. Por ejemplo, la población creció de 5,247 a 8,485, cifra última registrada en un padrón de confesión de 1797.25

La parroquia se encontraba en la vertiente del Pacífico, donde se ubicaba la cuenca del río Balsas que reunía un conjunto de tierras cálidas y templadas extendidas longitudinalmente frente al México Central. En las afluencias del río Balsas se desarrolló una importante agricultura, principalmente de granos y de azúcar. El desarrollo de estas actividades atrajo a gente de distintos orígenes socioétnicos conformada por indígenas, españoles, mulatos, coyotes, pardos y mestizos, como ya referimos y podemos apreciar en el siguiente cuadro. En el padrón de confesión de $\mathbf{1 7 9 7}$, las personas que no consignan su calidad en la cabecera corresponden en su 
mayoría a los hijos, en tanto en las haciendas y ranchos los esclavos aparecen sin calidad. Por su parte, en los pueblos el registro siempre especificó que era población indígena. Como se observa en el cuadro I, en los pueblos la cifra correspondiente a la población sin calidad es la más baja, aunque también se reportaron otras calidades (mestizos, castizos y pardos), igual que en el conjunto de los otros asentamientos del curato.

Cuadro i. Calidades registradas en la cabecera, pueblos y haciendas en la parroquia de San Agustín Jonacatepec, I797. Totales y porcentajes

\begin{tabular}{|c|c|c|c|c|c|c|c|c|c|c|c|c|}
\hline Localidad & Indios & $\%$ & Españoles & $\%$ & Mestizos & $\%$ & $\begin{array}{l}\text { Castizos, } \\
\text { mulatos, } \\
\text { castas y } \\
\text { pardos }\end{array}$ & $\%$ & $\begin{array}{l}\text { Sin } \\
\text { calidad } \\
*\end{array}$ & $\%$ & Total & $\%$ \\
\hline Cabecera & 298 & 33.7 & $5^{2}$ & 5.8 & 162 & I8.3 & 82 & 9.2 & 288 & 32.6 & 882 & IOO \\
\hline Pueblos & 5,955 & $94 \cdot 3$ & I8 & 0.2 & I49 & 2.3 & I 28 & 2.0 & 62 & 0.9 & $6,3 \mathrm{I} 2$ & IOO \\
\hline Ranchos & I & 0.3 & & & 90 & $35 \cdot 4$ & $2 \mathrm{I}$ & 0.2 & $\mathrm{I} 42$ & $55 \cdot 9$ & 254 & IOO \\
\hline $\begin{array}{l}\text { H. } \\
\text { Tenango }\end{array}$ & I 24 & 24.8 & I6 & 3.2 & 86 & 17.2 & 68 & 13.6 & $204^{* *}$ & 40.9 & 498 & IOO \\
\hline $\begin{array}{l}\text { H. Santa } \\
\text { Clara }\end{array}$ & I39 & 20.4 & $\mathrm{I} 2$ & I. 7 & 90 & $\mathrm{I} 3.2$ & IO7 & I5.7 & 333 & 48.8 & 68I & IOO \\
\hline Totales & 6,507 & 76.6 & 99 & I.I & 577 & 6.8 & 394 & 4.6 & 908 & I0.7 & 8,485 & IOO \\
\hline
\end{tabular}

* Una gran parte de los hijos, niños de pecho y párvulos aparecen anotados sin calidad. **En esta cifra se incluyen 9 individuos de "razón" y i5 esclavos sin calidad.

Elaboración propia con base en "Padrón general de toda la feligresía de Jonacatepec de españoles, castas e indios de pueblo y laboríos de haciendas y ranchos. I797". AHA, fondo Episcopal, sección Secretaría arzobispal, caja I4 CL, exp. 4, 50 fs.

Identificamos que en las haciendas y en la cabecera de la parroquia se reportó una diversidad de calidades conformadas en su mayoría por mestizos, indios, mulatos libres y pardos. Consideramos el término de calidad como un sistema de clasificación de la población sin que necesariamente refiera a rasgos físicos o biológicos. El término daba cuenta de una autoadscripción a una colectividad, como es el caso de residente de la cabecera, pueblos, hacienda o rancho. $\underline{\underline{26}}$ 
En zonas de tierra caliente y vecinas a esta parroquia, en Yautepec y Jiutepec la fuerte mortandad de indios dejó tierras vacantes para la población no india inmigrante. En estos lugares los indios fueron severamente afectados por las epidemias, lo que provocó un estancamiento de la población en las cabeceras, mientras los mestizos y otros grupos aumentaron su presencia. ${ }^{27}$ Es posible que en Jonacatepec haya ocurrido el mismo fenómeno, ya que registró un elevado número de no indios, principalmente de mestizos y castas. En San Agustín Jonacatepec el 74.3 \% de la población residía en los I7 pueblos sujetos y barrios de la parroquia. Este patrón de asentamiento muestra de qué manera estos lugares fueron aumentando en detrimento de la propia cabecera, que no contaba con tantos residentes. Lo anterior quizá obedezca al impacto de las epidemias y crisis, aunque en estos pueblos sujetos vivían sobre todo indígenas. En el padrón de I797, la población de la hacienda de Santa Clara Montefalco aparece en tres listas: primero, disponemos del "padrón de españoles, indios criollos y laboríos de la esclavonia", en el cual se registró a una población conformada por diferentes calidades y condición. Por su parte, en Santa Ana Tenango también se separó la población india de la no india. En Santa Clara predominan ligeramente las mujeres: 345 frente a 332 hombres, mientras en Santa Ana Tenango el padrón de los indios contabilizó 68 mujeres y 57 hombres, en tanto la población no india ascendía a I84 mujeres y i89 hombres. Es interesante señalar que en ambas haciendas se registraron "mestizos y mulatos libres". Por ejemplo, en Santa Clara aparecen 43 "mulatas libres" y 2 mestizos "libres"; las mulatas libres estaban casadas con esclavos. $\stackrel{28}{ }$ Cabe referir que a través del matrimonio con indios o mulatas libres muchos esclavos logaron obtener su manumisión.

Los datos disponibles permiten conocer algunas características de las familias. Por ejemplo, en el padrón de confesión de 1797 de la hacienda de Santa Clara Montefalco identificamos una pareja de mestizos, Francisca Xaviera y Mariano Rodríguez con cuatro hijos de i6, Io, 5 y 3 años. Las edades de los hijos fluctuaban entre los 4 a i 8 años. Son escasos estos ejemplos, ya que sólo se consignaron cinco matrimonios entre mestizos de un total de 96 parejas, de las cuales había un fuerte predominio de matrimonios entre pardos (28) y de pardos con mestizos (Io). La protección que podían ofrecer las haciendas puede comprobarse en el volumen de la población residente en las haciendas y en el mismo tamaño de las familias conformada por parejas con tres o más hijos. ${ }^{29}$ El esmero del hacendado Icazbalceta para llevar a un médico a inocular a su población trabajadora durante la epidemia de viruela de 1797 puede ser un indicio de que quizá en las haciendas la población gozaba de mayor protección.

\section{La diseminación de la viruela en la Nueva España}

Cabe referir que la década de 1790 no sólo estuvo marcada por la presencia de la viruela, sino también asediada por crisis de subsistencia, principalmente, en el valle de México y Puebla. I797 sería el año de mayor afectación de la enfermedad, ya que la epidemia fue atacando varias poblaciones del occidente, centro y norte de la Nueva España, al igual que otras localidades de gran tráfico comercial como Xalapa y el puerto de Veracruz. Otros lugares más pequeños también resultaron víctimas de la epidemia, como Tonalá, Córdoba, Matehuala, en el actual San Luis Potosí y Acayucan, en Veracruz. Para I798, la epidemia había llegado a las poblaciones norteñas de Saltillo y Zacatecas, en tanto seguía afectando las provincias del centro y sur del virreinato. ${ }^{30}$ 
Uno de los aspectos que llama la atención del estudio de la viruela de i797 es la abundante información histórica disponible: informes de virreyes, del cabildo, bandos, registros de enfermos e inoculados, así como impresos referidos a tratamientos curativos o preventivos contra la enfermedad. Gracias a esta valiosa documentación histórica se dispone de muchos estudios desde distintos enfoques. ${ }^{21}$ Cabe indicar que la viruela que se presenció en la Nueva España entre I794 y 1798 fue acompañada por otros fenómenos, como sequías y otro tipo de padecimientos. De las primeras referencias sabemos que el 22 de julio de 1796 en sesión de cabildo de la ciudad de Puebla se informó que la epidemia había llegado de Guatemala, donde se encontraron algunos enfermos de viruela procedentes de Perú. ${ }^{22}$ Es posible que así haya sido, en virtud de que los primeros lugares afectados fueron Oaxaca y Chiapas, que colindaban con la provincia de Guatemala. Todavía quedaría por indagar la ruta de diseminación desde Perú hasta Guatemala, Chiapas y Oaxaca. Empero, queda claro que la epidemia se fue extendiendo del sur hacia el centro y de ahí al occidente y norte. La vía de contagio hacia Puebla podría haber sido a través de Oaxaca. Al llegar a Puebla se fue extendiendo hacia Veracruz y la Ciudad de México.3z

Desde I794 se cuentan con reportes de viruela en varios pueblos de Tehuantepec, donde los indios solicitaron a la Real Audiencia la suspensión del pago de tributos debido a la epidemia que estaban padeciendo. ${ }^{34} \mathrm{Al}$ año siguiente, en 1795 , la meseta central de la provincia de Chiapas sería afectada por la viruela, ${ }^{35}$ mientras a mediados de dicho año otros pueblos de Tehuantepec fueron afectados por la enfermedad. En I796, la viruela había alcanzado Valladolid, en la provincia de Michoacán, que se encontraba hacia el occidente. Ahí la epidemia se prolongó hasta el año siguiente, aunque ahí al parecer tuvieron gran éxito las campañas de inoculación. ${ }^{36} \mathrm{Al}$ respecto, Humboldt señalaba que de los 6,80o inoculados en Valladolid, i7o personas no lograron sobrevivir a la enfermedad y fallecieron, atribuyendo su deceso a que probablemente al recibir la inoculación ya estaban contagiados por la viruela, pero estas cifras pueden confrontarse con documentos de otra naturaleza. Por ejemplo, una carta del intendente Díaz de Hortega al cabildo eclesiástico, le informaba que en tanto la viruela había causado graves estragos en la Ciudad de México, el número de enfermos en Valladolid no sobrepasaba 27 personas, de las cuales sólo fallecieron dos. ${ }^{37}$

Después de Chiapas y Tehuantepec, en el transcurso de los siguientes años la viruela se fue diseminando hacia Puebla y la Ciudad de México. Lo mismo ocurrió con los puertos de Veracruz y Acapulco, que fueron alcanzados por la enfermedad en i796. Al parecer, los brotes de viruela de 1794 y I798 sí afectaron población adulta, provocando estragos económicos. Por ejemplo, en I797 en Acayucan (Veracruz), una epidemia de viruela y "calenturas pútridas" causaron la muerte de I,400 almas "sin tener mano de obra para levantar las cosechas". ${ }^{8}$ Así, identificamos dos panoramas: I) aparecen localidades en el centro del virreinato en donde la epidemia pudo haber permanecido endémica y solo brotaba en época de calor y frío, afectando sobre todo a población infantil; 2) en otros lugares apareció de manera más virulenta matando a población económicamente activa. En el caso de Acayucan podemos atribuir las muertes a la otra enfermedad, es decir, a las "calenturas pútridas", aunque todavía queda por averiguar si se trataba del mismo padecimiento. Disponemos de varias referencias relativas a la aparición de la viruela junto con otras enfermedades, como tos, dolores de costado, "enfermedades peligrosas", tabardillo, "dolores pleuríticos", calenturas, entre otros. ${ }^{39}$ La ruta de diseminación de la viruela 
en la Nueva España entre I793 y I799 revela que se trató de un brote no endémico, sino de una fuerte epidemia de gran alcance, pues, contagió casi a todo el territorio: sur, sureste, altiplano central, Bajío, Occidente y Norte. El mapa de propagación de la epidemia del tomo i sobre El impacto demográfico la viruela, editado por El Colegio de Michoacán, revela otra ruta de difusión a través de diferentes puntos del Golfo y el sureste. En marzo de 1793, llegó a Campeche gente infectada por viruela y en febrero del siguiente año el padecimiento se difundió a Tabasco. En el transcurso de $\mathbf{7 9 4}$, la viruela se propagó lentamente por la sierra de Chiapas, donde había una baja densidad demográfica. Al llegar a los altos, la viruela se diseminó aceleradamente. Fue en agosto de 1796 cuando se tiene evidencia de la viruela en Xalapa, al llegar a ese punto se fue extendiendo hacia Puebla y la Ciudad de México, seguramente a través del camino de Oaxaca o Veracruz. En I797, varias localidades del altiplano central, donde estaba Jonacatepec, fueron alcanzadas por la viruela. En I797 y I798, la viruela se propagó hacia Valladolid, León, San Luis Potosí, Zacatecas y Durango. ${ }^{40}$

Como queda demostrado gracias a este tipo de estudios, las epidemias de viruela de r794 y r798 no sólo fueron relevantes por su gran extensión geográfica y su severo impacto demográfico, sino también porque en estos años se pusieron en práctica diversas medidas sanitarias y preventivas que de algún modo lograron aminorar los estragos de la enfermedad, tema que desarrollaremos en el siguiente apartado.

La inoculación y las víctimas de la viruela en Jonacatepec

A principios del siglo XIX, Alejandro Humboldt señalaba que el brote de viruela de I797 había sido menos mortal gracias a "que se practicó la inoculación en las inmediaciones de México". Algunos de los hospitales o casas establecidos durante la epidemia también se utilizaron para inocular a los enfermos. De los lugares en donde tuvo mayor éxito la inoculación fue en Valladolid y en varios pueblos del obispado de Michoacán. El propio obispo fray Antonio de San Miguel, ilustrado y promotor de una política más asistencial durante epidemias y desastres, empezó a persuadir a sus feligreses para que se inocularan. ${ }^{ \pm 1}$

En la capital del virreinato, la inoculación se llevó a cabo en el mes en que comenzó la viruela, en agosto de i797. Para tal objetivo se improvisó una casa para inocular a los enfermos. De acuerdo con Sedano, se enfermaron 70,0oo personas y sólo murieron 7,068. En los ocho cuarteles mayores de la ciudad se empezó a inocular a la población a través de juntas "subalternas de caridad" integradas por autoridades eclesiásticas y civiles, obteniendo buenos resultados. El ayuntamiento de la ciudad tuvo una labor importante en esta labor. ${ }^{22}$

La inoculación no sólo se practicó en los grandes centros urbanos del virreinato, sino también en localidades más pequeñas. Por ejemplo, en Teotitlán del valle, en Oaxaca, en el mes de septiembre de I797, cuando comenzó la viruela, se llevó a cabo la inoculación "con muy favorable éxito". Para ello se improvisó un hospital diferente a los que atendían a la población contagiada. Por su parte, en la localidad norteña de Saltillo, el cabildo sufragó los gastos para la inoculación. ${ }^{43} \mathrm{Al}$ respecto, el estudio de Machuca sobre Tehuantepec da cuenta del nivel de aceptación o no de la inoculación entre la población indígena. Es interesante ver cómo en la villa 
zapoteca de Tehuantepec tal práctica no fue bien recibida en los pueblos que tenían menos contacto con los españoles, como fue el caso de los mixes y zoques, quienes desconfiaron de la inoculación. ${ }^{44}$

Como señalamos al principio, desde I779, Esteban Morel había publicado un documento relativo a la inoculación como un método eficaz para prevenir la viruela. Este descubrimiento fue de tal relevancia que el propio virrey Branciforte impulsó la campaña de inoculación durante la viruela de i797 y i798. En el caso de la parroquia de Jonacatepec, sabemos que en noviembre de i797, el alcalde mayor de Cuernavaca informó al mismo virrey que el teniente del partido de Jonacatepec, don Antonio Montoto, dio órdenes al médico don Rafael Altieza Palacios "para la asistencia de los enfermos de aquel partido". De esta instrucción derivó el padrón de enfermos y muertos que se hizo en la parroquia, el cual utilizamos para evaluar los indicadores de mortalidad y letalidad, así como demostrar la efectividad o no de las prácticas de inoculación. ${ }^{45}$ Ante esta orden, el Br. Don Juan José Anaya, cura coadjutor y juez eclesiástico de la villa de Jonacatepec, informó que la viruela se estaba manifestando en la cabecera, sus cuatro pueblos y tres haciendas. Se indicaba que no se disponía de fondos propios y que la villa se encontraba "sumamente pobre para el mantenimiento de los asistentes en casa". El padrón de enfermos y muertos fue elaborado por el cura de la feligresía, Francisco Baroja, del cual seguramente Anaya se basó para emitir un informe general sobre el estado de la feligresía durante la epidemia. ${ }^{46}$ Los datos arrojados por el padrón de enfermos y muertos por la viruela revelan que la mayor afectación ocurrió en los pueblos sujetos, donde se asentaba la mayoría de los indígenas. Los datos procedieron de las visitas efectuadas al curato y de informes proporcionados por el cirujano encargado de la inoculación. 
Gráfica I. Total de muertos y contagiados por la epidemia en la cabecera y pueblos de la parroquia de Jonacatepec, I797 (porcentajes)

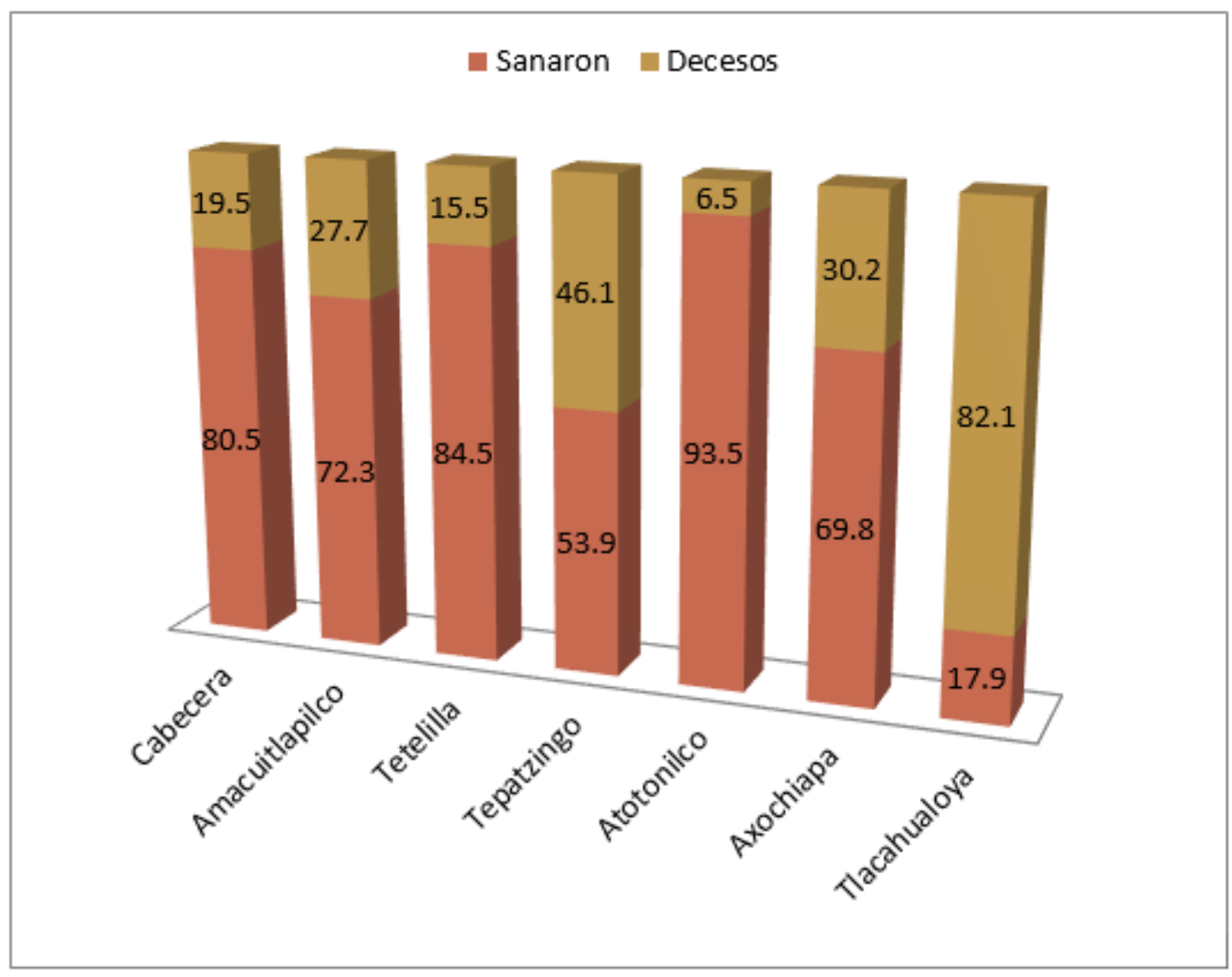

Elaboración propia con base en "Padrón general del partido de Jonacatepec de todos los sujetos que han muerto en la presente epidemia de viruelas y los que la han padecido, I797". AGN, Hospital de Jesús, leg. 265, núm. Io.

Nicolás Icazbalceta, dueño de las haciendas de Tenango y Montefalco, fue el principal promotor de la variolización en Jonacatepc. En sus empresas logró inocular a sus esclavos y trabajadores, aproximadamente zoo personas. Veremos qué, a pesar del gran número de contagios en estas dos haciendas, la tasa de mortalidad fue menor con respecto a la cabecera y pueblos sujetos. Por ejemplo, a principios de octubre de I797, el mismo Juan José Anaya señaló que en la hacienda de Santa Ana Tenango se inocularon "Io8 individuos entre esclavos y operarios libres, ninguno de ellos falleció". No obstante, esta cifra no coincide con el mismo padrón de enfermos y muertos, la cual reportó finalmente una cifra más alta, de 337 personas contagiadas y 29 decesos. ${ }^{47}$ El cura J. Anaya se refirió a que en la cabecera habían muerto 280 y se presumía "que en la cama había i6o personas", de las cuales ignoramos si fallecieron o no. El informe se hizo el 5 de octubre. ${ }^{48}$ Es importante referir que en el padrón de enfermos y muertos se arrojó una cifra menor de muertos en la cabecera, izo individuos, dato que incluía II5 indios que habían fallecido más 15 decesos entre "españoles y castas". ${ }^{49}$ En virtud de que desconocemos la procedencia del número de muertos proporcionada por el cura Juan José Anaya, nos basamos en el registro de enfermos y muertos elaborado por Francisco Baroja, cuyas cifras permite un análisis 
comparativo con el padrón de confesión elaborado unos meses atrás. Estas inconsistencias de las cifras entre los informes generales y el mismo padrón podrían obedecer a la misma fecha de elaboración del padrón, el cual debió levantarse a fines de octubre de 1797.

La documentación histórica suele atribuir a que la población indígena era más renuente a la inoculación. Esta misma apreciación puede responder al hecho de que en Jonacatepec el padrón de enfermos y muertos por viruela sólo haya registrado i5 muertos entre "españoles y castas". 50 Cabe mencionar una experiencia similar ocurrida en algunos pueblos de Tehuantepec, donde los indios también se opusieron a recibir la inoculación. Finalmente se inocularon a 199 personas de las cuales sólo murieron once, en contraste con 748 que no aceptaron inocularse y fallecieron 287. $5 n$ Guanajuato se dio otro caso de rechazo a la inoculación y que no necesariamente tenía que ver con los indios. En octubre de I797, Juan de Riaño, el intendente, emprendió un programa de inoculación para proteger a los niños contra la enfermedad, pese a que muchos padres se negaron a inocular a sus hijos. Y para dar un ejemplo el intendente inoculó a sus seis hijos. ${ }^{52}$

Al analizar el padrón de enfermos y muertos de viruela de 1797 en Jonacatepec identificamos que la mayor parte de la población de la parroquia eran niños menores de siete años. Este fuerte predominio se corrobora con el padrón eclesiástico, el cual como ya referimos presumimos que fue realizado a principios de abril, es decir, antes del brote epidémico. En el caso de Santa Clara Montefalco el 59 \% y en el de Santa Ana Tenango el 44.4 \% eran menores de siete años. Los padrones de confesión se llevaban a cabo durante el periodo de la cuaresma. Como se ha indicado, presumimos que la fecha aproximada de la elaboración de enfermos y muertos por viruela fue a fines de octubre, en virtud de las fechas de los informes y cartas que acompañaron al documento. De esta manera consideramos que ambas fuentes pueden brindar un panorama general del impacto diferencial de la viruela, como veremos a continuación.

Cuadro 2. Tasas brutas de mortalidad y total de muertos por la viruela de i797. Curato de Jonacatepec

\begin{tabular}{|l|l|l|l|}
\hline Localidad & Población 1797 & Total de muertos & TBM \\
\hline Cabecera & 882 & I30 & I 47.3 \\
\hline P. Tetelilla & 359 & 40 & III.4 \\
\hline P. Atotonilco & I4I & 3 & 2 I.2 \\
\hline P. Tepazingo & I82* & $286 *$ & -I.57 \\
\hline Tlacahualoya & I,2I7 & IO5 & 86.2 \\
\hline
\end{tabular}




\begin{tabular}{|l|l|l|l|}
\hline Axochiapa & I,206 & 333 & $276 . \mathrm{I}$ \\
\hline H. Santa Clara & $68 \mathrm{I}$ & 24 & 35.2 \\
\hline H. Sta. Ana Tenango & 498 & 29 & 58.2 \\
\hline H. Ignacio & No hay datos & 7 & \\
\hline Totales & 3,960 & 624 & I57.5 \\
\hline
\end{tabular}

* La tasa bruta de mortalidad es un índice calculado para reflejar la cantidad de muertes de un año por cada mil habitantes. La fórmula es total de fallecimientos entre población total por mil.

* En el pueblo de Tepazingo se observa un subregistro de la población reportada en el padrón, o bien la cifra de muertos de viruela está alterada. De ahí que reporte una tasa negativa.

El número de decesos y de personas que lograron librar la enfermedad en los pueblos contrasta con la situación experimentada en las haciendas. El hacendado don Nicolás Icazbalceta, vecino y dueño de Santa Clara Montefalco, "trajo un médico y un cirujano". Este facultativo logró inocular a varios esclavos y operarios "libres". En el padrón elaborado por Baroja durante la epidemia se reportaron en la hacienda de Tenango 337 personas contagiadas, de las cuales sólo murieron 29 individuos. 53 
Gráfica 2. Cabecera de Jonacatepec. Total de indios muertos y los que sanaron por la viruela de 1797

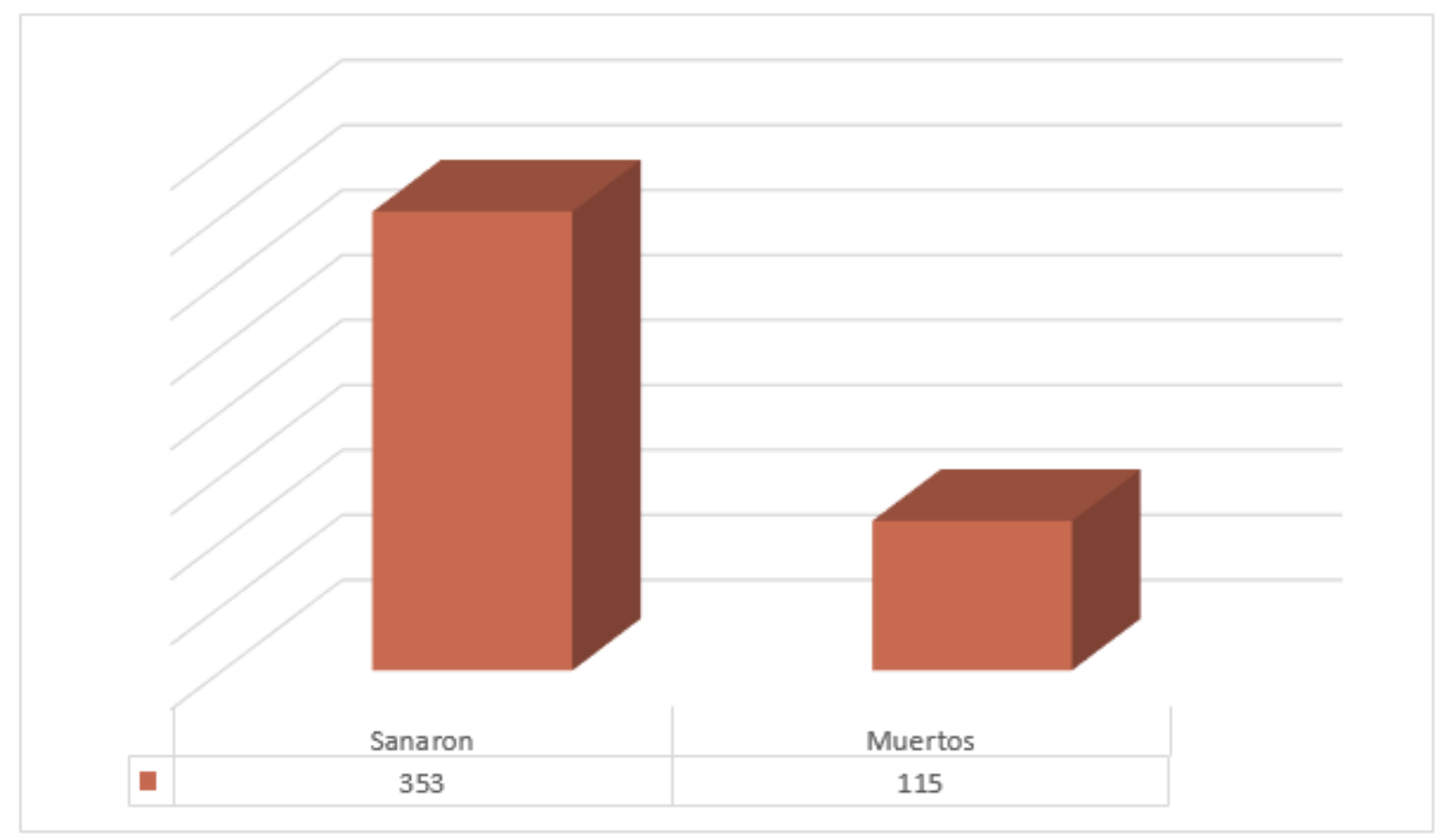

Para ahondar más en las características de la epidemia, el cura Anaya profundizó en su sintomatología. En un extenso informe que remitió al teniente del partido describió con gran detalle que estas viruelas se caracterizaban por "ulceras, pintas, moradas, chatas y cristalinas y otros con puntas negras, de las que se han experimentado por ser de la calidad más criminosa han fallecido los más". ${ }^{54}$ Es importante señalar que en la misiva se indicaba que entre los indios no se "había podido practicar la operación", es decir, no fueron inoculados. Por esta circunstancia habían fallecido un gran número de indios, como se refleja en la gráfica 2. En contraste, según el mismo informe del cura, la inoculación entre "la gente de razón" había arrojado "felices éxitos", principalmente, en la población asentada en la propia cabecera, donde sólo se reportaron i5 decesos.

A pesar de que no fue objeto de este estudio, es importante referir el caso de Jantetelco, parroquia vecina, donde hacia el 25 de octubre de 1797 se reportaron 327 casos, de los cuales murieron izo. En dicha parroquia se señalaba que no había fondos suficientes para hacer frente a la epidemia, ni tampoco contaban con médico cirujano sangrador, ni botica. En este lugar se carecía de "casas de campo o asilos" a donde llevar a los enfermos, ni tampoco "había los medios para transportarlos". Sin embargo, el teniente del partido, Montoto, informó que en la cabecera de Jonacatepec y tres pueblos sí se había logrado inocular a la población, principalmente en las haciendas. Se hizo referencia al método Buchan para curar "las viruelas naturales", el cual consistía en suministrar una "bebida ordinaria el palo mulato del que se ha experimentado muchas utilidades", el cual se comprobó su eficacia en la cabecera de Yecapixtla, que también se encontraba azotada por la viruela..$^{56}$ 
Uno de los indicadores para evaluar la virulencia de una enfermedad son las tasas de letalidad. El padrón de enfermos y de los que sanaron permite hacer dicho cálculo, como se aprecia en el cuadro 3. Se observa que la mayor afectación de la viruela ocurrió en el pueblo de Axochiapa, seguido de Tepatzingo, Tlacahualoya y Amacuitlapilco. Los tres lugares que reportaron la tasa bruta de mortalidad más elevada fueron: la cabecera, los pueblos de Tetelilla, Tlacahualoya y Axochiapa (véase cuadro 2). Estos lugares concentraban un gran número de indígenas. No obstante, en Tepatzingo se reportaron 286 muertos, cifra muy por arriba del total de población registrada en el padrón de 1797 con un total de 182 personas, como se aprecia en el cuadro 3. Podemos presumir que el padrón de enfermos quizá haya sobrestimado el número de muertos. No sobra referir la propia apreciación del cura y médico, quienes señalaron la fuerte resistencia de los indios a ser inoculados y las maravillas de este método para librar la enfermedad.

Cuadro 3. Tasa de letalidad por la viruela de i797. Curato de Jonacatepec

\begin{tabular}{|c|c|c|c|}
\hline Localidad & Total de casos registrados & Total de muertos & Tasa de letalidad* \\
\hline Cabecera & 689 & I3O & $19 \cdot 9$ \\
\hline P. Tetelilla & 258 & 40 & I5.5 \\
\hline P. Atotonilco & 46 & 3 & 6.5 \\
\hline P. Tepazingo & 620 & 286 & $46 . \mathrm{I}$ \\
\hline Tlacahualoya & 587 & I05 & 17.8 \\
\hline Amacuitlapilco & $27 \mathrm{I}$ & 75 & $27 \cdot 6$ \\
\hline Axochiapa & 333 & I94 & 58.2 \\
\hline H. Santa Clara & $28 \mathrm{I}$ & 24 & 8.5 \\
\hline H. Sta. Ana Tenango & 337 & 29 & 8.6 \\
\hline H. Ignacio & I37 & 7 & $5 . I$ \\
\hline Totales & 3523 & 893 & 29.6 \\
\hline
\end{tabular}

* Tasa de letalidad es la proporción de personas que mueren por una enfermedad entre el total de los afectados por la misma en un periodo y área determinada 
En este análisis interesa resaltar el impacto de la viruela por residencia, calidades y grupos de edad. Así, en la cabecera el padrón de confesión registra que el i $8.9 \%$ del total de la población era menor de i4 años, mientras en los pueblos considerados en el padrón de enfermos y muertos identificamos que un $30.5 \%$ estaba por debajo de esa edad. ${ }^{57}$ La gráfica 3 muestra que la viruela fue más severa con los niños de o a 4 años y de 5 a 9 años, mientras su afectación fue menor en los demás grupos de edad.

Gráfica 3. Total de contagiados por la viruela de i797 por grupos de edad y sexo.

Cabecera y pueblos de la parroquia de Jonacatepec

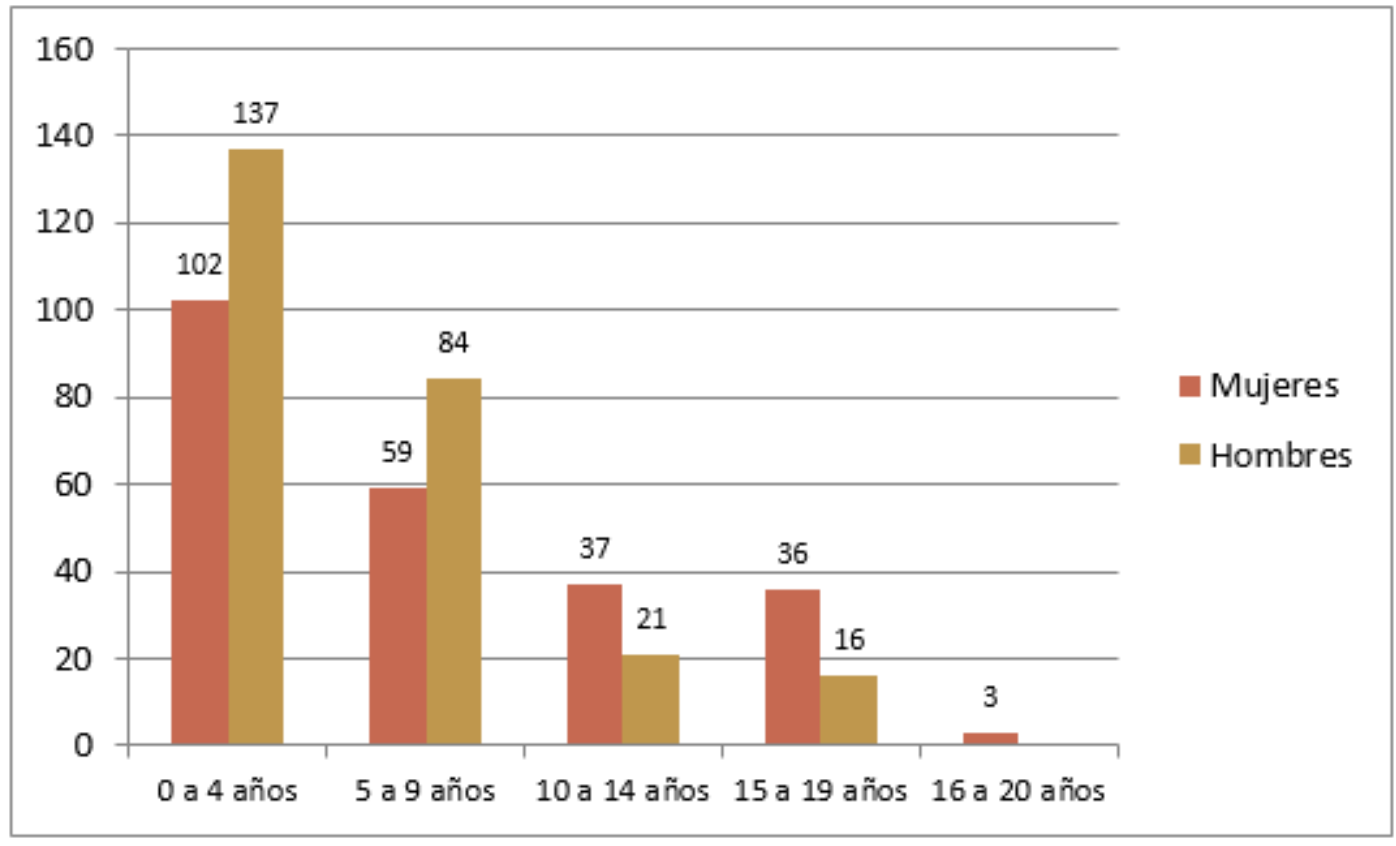

Elaboración propia con base en "Padrón general del partido de Jonacatepec de todos los sujetos que han muerto en la presente epidemia de viruelas y los que la han padecido, I797". AGN, Hospital de Jesús, leg. 265, núm. Io.

La gráficas I y el cuadro 2 revelan que la viruela afectó en mayor grado a los indios residentes de la cabecera y pueblos, en comparación con la "gente de razón" o no indios asentados en la misma cabecera y las haciendas. Como ya reiteramos, cabe destacar los pueblos de Tlacahualoya, Tetelilla y Axochiapa, donde la tasa bruta de mortalidad fue de las más altas. Por ejemplo, Axochiapa con la tasa bruta de mortalidad más alta reportó en el padrón de confesión de 1797 un importante número de niños de "pecho", 34 bebés de meses, I50 niños de i a 4 años, es decir, un total de i 84 niños eran menores de 4 años. Había 255 niños de 5 a 9 años; 90 personas de io a I4 años; y 75 individuos de 15 a 20 años. Es interesante desglosar estos grupos de edad, en virtud de que el $66.4 \%$ de la población registrada con la edad era menor de 9 años..$^{8}$ De ahí entonces que podemos atribuir esta elevada tasa de mortalidad por la gran cantidad de niños menores que había en el pueblo. 
Por su parte, en Tetelilla con in. 4 de tasa de mortalidad los grupos de edad registrados se distribuyeron de la siguiente manera: o a 4 años (73); 5 a 9 (82); io a I4 (30); y I5 a 20 (20). Así, en dicho pueblo el 78.6 \% de la población reportada con edad era menor de nueve años. Tlacahualoya reportó también una tasa elevada con 86.2 por mil. Ahí también se concentraba una población numerosa con un $22.4 \%$ de personas menores de 14 años. El caso de Tepatzingo también es importante señalarlo, aunque en este caso no podamos relacionar las cifras de habitantes con el total de muertos por la viruela. El padrón de confesión de i797, a pesar del fuerte subregistro de la edad, da cuenta de los siguientes grupos de edad: o a 4 años (I7); 5 a 9 años (35); IO a I4 años (I8); I5 a I9 (6); 20 a 24 años (4); y de 25 a 29 (2). El 62.7\% de la población registrada eran menores de 9 años y el 2 I.9 de io a I4 años. Ya señalamos que en este caso el número de muertos sobrepasó al total de población registrada en el padrón de i797.

En las haciendas, la proporción de niños y jóvenes era la siguiente: en Santa Clara, los españoles, mestizos y castas laboríos menores de i4 años alcanzaban sólo el $5.6 \%$ del total de habitantes, en tanto en la hacienda de Santa Ana Tenango esta cifra era más elevada. Por ejemplo, en el resumen del padrón de confesión de 1797 se registraron 9I "infantes". La proporción con el total de habitantes arroja el siguiente resultado: entre los indios de la hacienda, los niños y jóvenes (de o a I4 años) llegaban al 30.4\% del total de población, mientras entre los esclavos el porcentaje era mayor, es decir, alrededor del 69.52 \%. En tanto en la hacienda de Santa Clara Montefalco, los menores de I4 años representaban el $29.9 \%$ de la población total. Cabe destacar el fuerte subregistro de población adulta en el padrón de I797, en virtud de sólo se reportaron 26 personas mayores de 15 años. ${ }^{59}$ Las edades de los padres no aparecen registradas en el padrón de 1797 sin que hasta el momento podamos precisar la causa de esa omisión. Lo anterior quizá fue debido a la naturaleza y objetivo del mismo padrón, pues, al ser un padrón de confesión interesaba reportar la edad de las personas que estuvieran listas a recibir la comunión.

Podemos considerar otra reagrupación de la población menores de siete años y llegamos a resultados similares. En Santa Clara Montefalco se contabilizaron 39 niños menores de siete años, cifra que representa el $59 \%$ del total de la población reportada con edad. En tanto, en Santa Ana Tenango tenemos 20 niños menores de siete años, o sea el $44.4 \%$ del total de registros que consignan la edad. Los siguientes grupos de edad se distribuyeron de esta manera: en Santa Clara Montefalco de 7 a I4 años había i6 personas y de 15 años en adelante 25 casos; en Santa Ana Tenango había I6 personas entre 7 y I4 años y II individuos mayores de I5 años. El individuo más grande registrado en Santa Clara Montefalco tenía 26 años y el más pequeño era un niño de pecho. Cabe indicar que en el $53.6 \%$ del total de habitantes de la hacienda se desconoce la edad. Para la población india de Tenango el porcentaje de personas sin edad es mayor, $65.6 \%$. El individuo más grande es un soltero de 25 años y el más pequeño de un año. En la población no india de la hacienda el porcentaje de quienes consignaron la edad es más alta, 46.9\%. El individuo mayor es un soltero de 28 años y los más jóvenes dos bebés de 6 meses. Resulta complicado elaborar pirámides de edad a partir de estos datos, pero sí queda claro la fuerte omisión de la edad en la población adulta. Si bien estamos conscientes de este problema creemos que podemos extraer ciertos resultados sobre el impacto de la viruela de 1797 y el alcance de la inoculación como una medida eficaz para frenar los contagios, como veremos más adelante. 
Las edades reportadas en el padrón de confesión constituyen un dato valioso porque permite conocer la proporción de niños y jóvenes en cada uno de los asentamientos. Las prácticas de inoculación en la zona se dirigieron hacia ese sector de la población, lo que probablemente evitó mayores estragos entre estos grupos de edad. Como hemos constatado, los grupos más vulnerables a la viruela fueron los sectores de o a 4 años y de 5 a 9 (gráficas 4 y 5 ). En el real de minas de Bolaños, David Carbajal también estudia el fuerte impacto demográfico de este brote de viruela en párvulos y niños menores de cuatro años. La misma situación se observa en Tehuantepec, donde murieron 566 menores de edad. En el valle de Toluca, Canales muestra que murieron más párvulos que adultos, tanto indios como españoles. $\frac{60}{}$

Gráfica 4. Población contagiada por la viruela en la hacienda de Santa Clara

Montefalco, I797

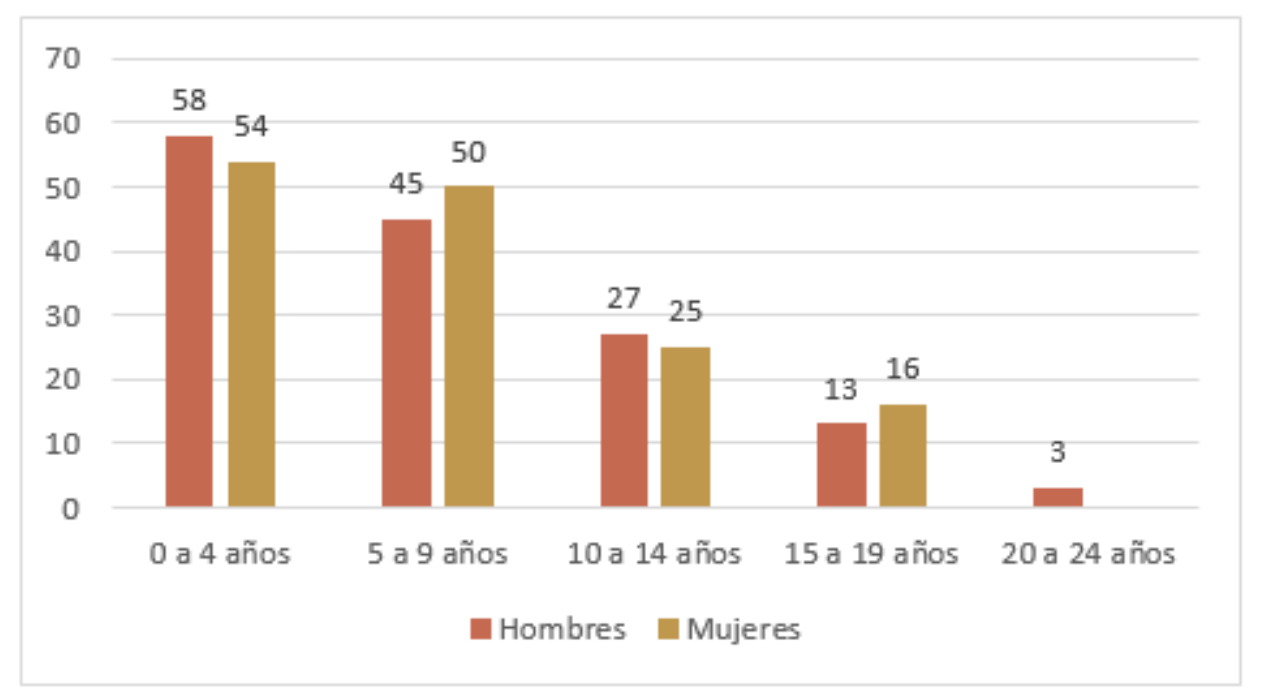

Elaboración propia con base en "Padrón general del partido de Jonacatepec de todos los sujetos que han muerto en la presente epidemia de viruelas y los que la han padecido, I797". AGN, Hospital de Jesús, leg. 265, núm. Io. 
Gráfica 5. Población contagiada por la viruela en la hacienda de Santa Ana Tenango,

1797

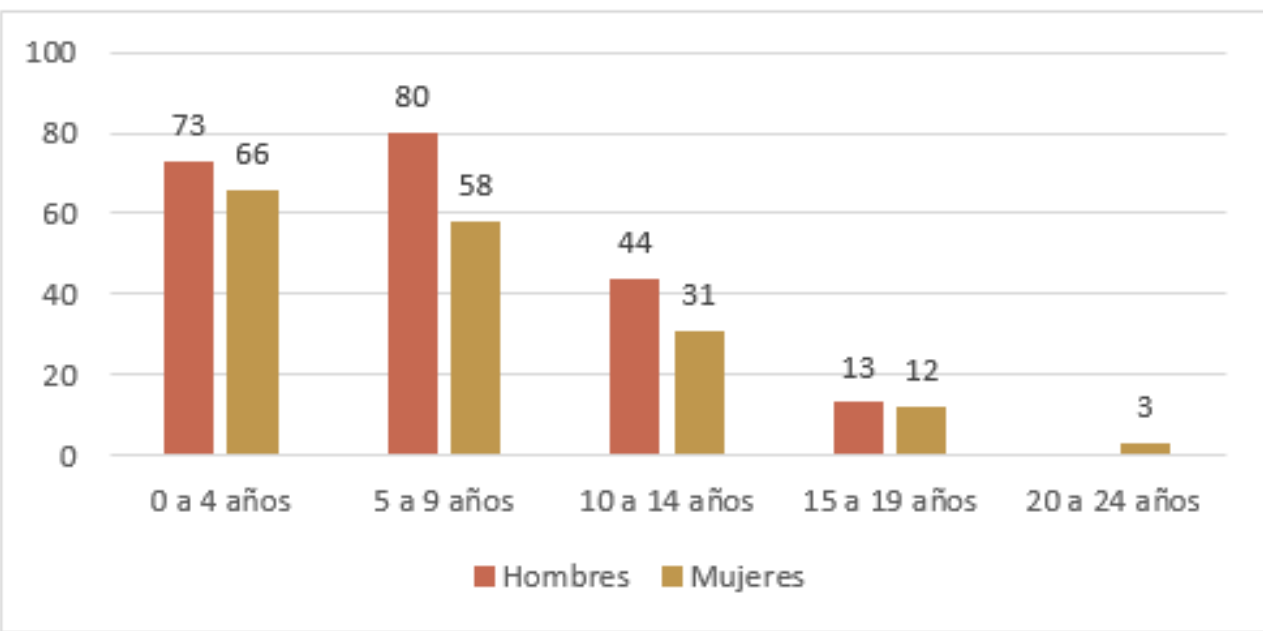

Elaboración propia con base en "Padrón general del partido de Jonacatepec de todos los sujetos que han muerto en la presente epidemia de viruelas y los que la han padecido, I797". AGN, Hospital de Jesús, leg. 265, núm. Io.

No hay duda de que uno de los objetivos de la elaboración del padrón de "viruelas" era mostrar el éxito de las prácticas de la inoculación. En cuanto al sexo, cabe indicar que entre los españoles y castas de la cabecera hubo más niños afectados, en contraste con la población indígena en la que se reportaron mayor número de contagios entre las niñas. En relación con este sector, tal como se muestra en la gráfica 2, entre los indios se reportó el mayor número de decesos. En la documentación histórica se indicaba que esta población fue más renuente a la inoculación. Coincidimos con el planteamiento de García Flores en torno a interrogarse hasta qué grado la viruela afectó en mayor grado a los indios. Empero, sí podemos suponer que los grupos de edad que no recibieron la inoculación o bien no habían sido atacados por el brote anterior fueron más vulnerables al contagio.

La comparación del total de muertos y los que sanaron o convalecientes en la cabecera y las haciendas de Santa Clara y Santa Ana Tenango arroja resultados similares, pues el número de decesos fue inferior al número de personas que finalmente sanaron. Al comparar los datos con el padrón de 1797 no deja de llamar la atención el gran número de niños que residían en la cabecera, aunque estas cifras no eran tan cuantiosas en las haciendas. Si comparamos ambos documentos podemos ver que en el padrón de i797 hubo un marcado subregistro de la población infantil en ambas haciendas, pues el padrón de enfermos y muertos de viruela reporta un mayor número de niños afectados. También es interesante señalar que bajo un espíritu ilustrado y práctico, el hacendado Icazbalceta tuvo un papel importante para procurar por la salud de sus trabajadores. En este sentido, era fundamental que la producción de sus haciendas no resultara afectada por esta terrible enfermedad, la cual a lo largo de su presencia en la Nueva España había provocado graves estragos en la población. 
Gráfica 6. Total de muertos y convalecientes por la viruela en la cabecera y haciendas de Jonacatepec, 1797

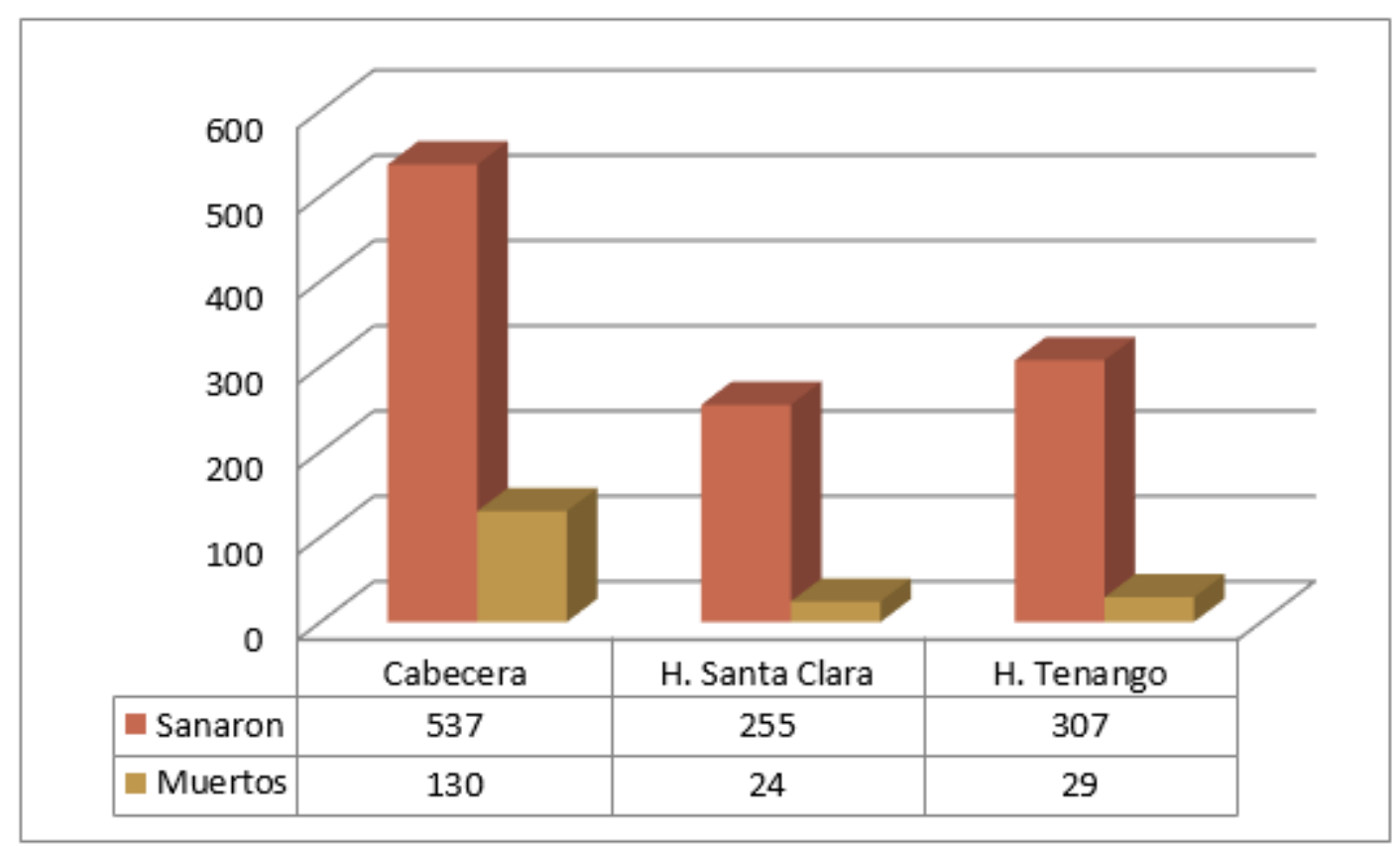

Elaboración propia con base en "Padrón general del partido de Jonacatepec de todos los sujetos que han muerto en la presente epidemia de viruelas y los que la han padecido, I797". AGN, Hospital de Jesús, leg. 265, núm. Io.

Al confrontar el total de convalecientes y decesos entre la cabecera y las dos haciendas podemos presuponer que la inoculación fue muy efectiva en estas últimas. También debemos considerar que la cabecera concentraba mayor número de residentes. Este aspecto se comprueba precisamente cuando calculamos las tasas brutas de mortalidad y letalidad (cuadros 2 y 3). Las tasas de letalidad del cuadro 3 permiten apreciar el fuerte impacto que provocó la viruela en la población asentada en los pueblos en donde residía la mayoría de los indígenas, como ocurrió en la cabecera y los pueblos de Tetelilla y Axochiapa. Las haciendas de Santa Clara y Santa Ana Tenango reportaron un gran número de contagios, pero al decir del registro de enfermos murieron muy pocos, 24 y 29 respectivamente. En esta empresa el padrón de 1797 registró varias familias con más de tres hijos menores y una composición plural de indios, pardos, mestizos y

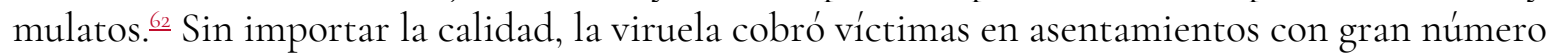
de residentes. No obstante, las haciendas de Santa Clara Montefalco y Santa Ana Tenango reportaron una cifra importante de contagios. ¿A qué se debió que el número de decesos haya sido menor? Varias cuestiones pueden aventurarse. Primero, al éxito de la inoculación, aunque ésta se implementó en medio de la diseminación de la viruela. Segundo, la cifra de enfermos podría haber correspondido al número de casos que adquirieron la viruela por la misma inoculación, pero de manera atenuada. La instrucción para elaborar el registro de enfermos y muertos fue muy clara en que se distinguiera los fallecidos y los que habían sanado. ${ }^{63}$ De tal suerte que podemos ver de qué manera este mismo registro tenía el propósito de comprobar con datos duros el éxito de la inoculación para combatir la viruela. 
En el padrón de enfermos y muertos aparece reportada otra hacienda llamada Ignacio, donde se contagiaron I48 individuos, de los cuales lograron librar la enfermedad i29 y no se contagiaron cuatro. .44 No tenemos datos de población de este asentamiento en el padrón eclesiástico de 1797 (véase cuadro 3). De igual forma, en el padrón de enfermos y muertos por la viruela no se reportaron cifras de los diez ranchos registrados en el padrón de confesión de i797 y en donde residían 3io personas, cifra que representaba el 3.5\% de la población total. Quizá por esto mismo no fue objeto de atención por parte de las autoridades durante el brote epidémico.

La relación entre el total de muertos con las cifras de habitantes registradas en el padrón de confesión de 1797 permite visualizar el impacto diferencial de la viruela, el cual puede corresponder con los grupos de edad, principalmente de niños y niñas menores de i4 años. También podemos presuponer que la inoculación logró aminorar las tasas de letalidad en las haciendas, donde sus trabajadores recibieron al médico, en contraste con los pueblos y la cabecera, cuyos residentes fueron más renuentes a ser inoculados.

\section{Conclusiones}

Uno de los objetivos del artículo fue mostrar hasta qué grado la inoculación logró aminorar el impacto letal de la viruela en la parroquia de Jonacatepec, una localidad rural con una presencia significativa de población de distintos orígenes socioétnicos. Esta experiencia fue importante, en virtud de que este tipo de medidas se implementaron sobre todo en las grandes ciudades del territorio novohispano. La existencia de informes y estadísticas que de manera pormenorizada contabilizó el número de enfermos, inoculados y muertos revela este interés de los gobernantes y ciertos sectores sociales ilustrados por conocer y tener un control de la salud y situación sanitaria de sus dominios. Las autoridades solicitaron a los cabildos y otras instancias de gobierno este tipo de informes, aunque cada autoridad envió a su modo de entender este tipo de estadísticas, pues, no existió un formato único. En el caso de Jonacatepec observamos este informe pormenorizado y una de sus virtudes es que registra la edad, sexo y calidad de los enfermos, muertos, y de que lo sanaron por tipo de asentamiento, datos que nos permitieron analizar el impacto diferencial de la viruela. En Durango también se llevaron a cabo estos registros detallados sobre el número de indios inoculados, fallecidos y que lograron librar la epidemia. ${ }^{65}$

La experiencia en otros lugares podría hacernos pensar en el éxito de la inoculación. Por ejemplo, en Guanajuato de los I3,I85 empadronados, se inocularon a II,OI5 personas, de las cuales murieron 85 , mientras que 840 fallecieron de "viruelas naturales", es decir, contagios adquiridos por la misma enfermedad y no por la inoculación. $\frac{66}{}$ Por su parte, García Flores señala que en Monterrey ingresaron al Hospital de Pobres ior inoculados, de los cuales sólo murieron 2, los demás libraron la enfermedad. En la ciudad norteña se inmunizó a 40.5\% de la población y sólo se contagió el ro \% de sus habitantes. Así, la viruela no se propagó más al norte de la ciudad de Durango gracias a que el obispo llevó a cabo una campaña de variolización. ${ }^{67}$

Por otro lado, algunos autores han señalado que deben cuestionarse las cifras de algunos informes de inoculados y enfermos. En la capital del virreinato, Ana Cecilia Rodríguez 
"considera insuficientes y ambiguas" los datos para asegurar el éxito de la inoculación, en tanto otros estudios muestran el éxito de ésta entre la población infantil. ${ }^{68}$ Igual sucede con la Ciudad de México, donde Luz María Espinosa y Raúl Miranda señalan que el impacto de la letalidad de viruela de I796-I798 estuvo vinculada con las actividades sanitarias y de inoculación impulsadas por la Junta Principal de Caridad. La inoculación fue aceptada en mayor grado por las clases altas de la ciudad. .99

En el caso de Jonacatepec podemos pensar en los beneficios que podría haber tenido la inoculación, aunque también es importante considerar que el nivel de concentración demográfica fue un factor determinante en el agravamiento del contagio de la viruela, así como la presencia de niños menores de i4 años. En Jonacatepec, la mayor tasa de mortalidad y letalidad ocurrió en la cabecera, así como en los pueblos de Axochiapan, Tepazingo y Tlacahualoya, donde los indios se negaron a recibir la inoculación y había población joven no inmunizada. El trabajo de García Flores sobre la capital neolonesa muestra que ahí el brote de viruela de i798 fue menor, en contraste con zonas marginales y alejadas de la capital. .0 $^{\circ}$ Por el contrario, nuestro estudio aporta cifras importantes de muertos y enfermos en la cabecera, donde podríamos haber presumido que la atención médica fue mejor. No hay duda de que la campaña de variolización fue exitosa en las haciendas Montefalco y Tenango, donde se reportaron menos muertos. Así, este artículo aporta una evidencia más de los beneficios que podría haber logrado la inoculación para contrarrestar el impacto de la viruela. Desgraciadamente, sólo contamos con este padrón de enfermos y no disponemos de la serie de entierros de la parroquia para corroborar con otras evidencias históricas, aunque en el mismo padrón de enfermos y muertos se menciona que el registro fue proporcionado por el cura de la parroquia, Br. Don Juan José Anaya, y quien -como vimos- remitió varios informes y cartas sobre el estado de salud en su jurisdicción. Por esta circunstancia, consideramos que puede ser una fuente confiable dado su conocimiento de la feligresía. Hasta el momento no tenemos conocimiento si en la zona de estudio se llevaron a cabo otro tipo de medidas para combatir la viruela, como fue el caso del aislamiento y traslado de enfermos a los lazaretos, medidas que proliferaron en muchas otras ciudades del virreinato. Sin embargo, las acciones emprendidas en esta parroquia revelan también un cambio de actitud y de mentalidad de los gobernantes y personas para combatir a este viejo flagelo que a lo largo de varios siglos había diezmado a la población. Pero, a pesar de estas campañas y acciones, el temor a inocularse o vacunarse era manifiesto, como a la fecha puede ocurrir. No debe sorprendernos que en aquellos años este miedo fuera más evidente.

\section{Agradecimientos}

Agradezco a los dictaminadores anónimos por sus valiosas críticas y atinadas observaciones al texto, las cuales ayudaron sustancialmente a mejorarlo.

Fuentes y bibliografía

Archivo del Ayuntamiento de Puebla (AAP), Actas de cabildo.

Archivo General del Estado de Oaxaca (AGEO), Tesorería Municipal. 
Archivo General de Indias, Sevilla (AGI), Indiferente General.

Archivo General de la Nación (AGN) Hospital de Jesús Reales cédulas.

Archivo Histórico del Arzobispado de México (AHAM), Episcopal, sección Secretaría Arzobispal, caja I4 CL, exp. 4, 50 fs.;

. Episcopal, sección Secretaría Arzobispal, caja I4 CL, exp. 3, 75 fs.

Archivo Histórico de la Biblioteca Nacional del Instituto Nacional de Antropología e Historia (AHBINAH).

Archivo Municipal de Saltillo (AMS), Presidencia Municipal.

Biblioteca Nacional de la Universidad Nacional Autónoma de México (BNUNAM), Fondo Reservado, Sala Mexicana.

AGOSTONI, Claudia. Médicos, campañas y vacunas. La viruela y la cultura de su prevención en México, 1870-1950. México: Universidad Nacional Autónoma de México, Instituto de Investigaciones Dr. José María Luis Mora, 2016.

. "Smallpox Eradication in Mexico". Latin American History, Oxford Research Encyclopedia. Latin American History (Oxford: Oxford University Press, 2016), I-25.

ALBERRO, Solange y Pilar GONZALBO. La sociedad novohispana. Estereotipos y realidades. México: El Colegio de México, 2or3.

BRAVO UGARTE, José. Historia sucinta de Michoacán. Morelia: Morevallado, 1995.

CAMACHO ALBERTO, Neibeth. "Guanajuato y Valladolid de Michoacán durante la epidemia de viruela de I797-I798”. En El impacto demográfico de la viruela en México de la época colonial al siglo XX, ed. Chantal Cramaussel, 93-ı04. México: El Colegio de Michoacán, 20 Io.

CANALES GUERRERO, Pedro. "Historia natural y cultural de la viruela y otras enfermedades infecciosas. Epidemias y endemias en el valle de Toluca, I690-I833". En El impacto demográfico de la viruela en México de la época colonial al siglo XX. Vol. III, ed. Chantal Cramaussel y David Carbajal López, 4I-62. México: El Colegio de Michoacán, 20 Io.

CARBAJAL LÓPEZ, David. La población en Bolaños, 1740-1848. México: El Colegio de Michoacán, 2008.

."Las epidemias de viruela en Bolaños, I762-1840", Relaciones Estudios de Historia y Sociedad XXIX (II4) (2008): 2I-43. 
Cartas de Cabildo Hispanoamericanos: Audiencia de México (siglos XVIII-XIX), vol. II, comp. Enriqueta Vila Vilar y María Justina Sarabia Viejo. Sevilla: Consejo Superior de Investigaciones Científicas, Escuela de Estudios Hispanoamericanos, I990.

CRAMAUSSEL, Chantal, "Introducción". En El impacto demográfico de la viruela en México de la época colonial al siglo XX. La viruela antes de la introducción de la vacuna. Vol. I, ed. Chantal Cramaussel, II-25. Zamora: El Colegio de Michoacán, 20 Io.

ed., El impacto demográfico de la viruela en México de la época colonial al siglo XX. La viruela antes de la introducción de la vacuna. Vol. I. Zamora: El Colegio de Michoacán, 2010.

CRAMAUSSEL Chantal y David CARBAJAL LÓPEZ, ed. El impacto demográfico de la viruela en México de la época colonial al siglo XX. Vol. III. Zamora: El Colegio de Michoacán, 20 oro.

COOK, Sherbune F. "The smallpox epidemic of I797", Bulletin of the History of Medicine (7) (1939): 937-969.

"La epidemia de viruela der797 en México". En Ensayos sobre la historia de las epidemias en México. Enrique Florescano y Elsa Malvido, 298-299. México: Instituto Mexicano del Seguro Social, I982.

COOPER, Donald. Las epidemias en la ciudad de México, 1761-1813. Colección Salud y Seguridad Social. Serie Historia. México: Instituto Mexicano del Seguro Social, I980.

ESPINOSA CORTES, Luz María y Raúl MIRANDA OCAMPO. "La epidemia de viruela de I796-I798. De Teotitlán del Valle, Oaxaca a la Ciudad de México”. En El impacto demográfico de la viruela en México de la época colonial al siglo XX. Vol. I, ed. Chantal Cramaussel, 7I-92. Zamora: El Colegio de Michoacán, zoro.

GARCÍA ACOSTA, Virginia, Juan Manuel PÉREZ ZEVALLOS y América MOLINA DEL VILLAR. Desastres agrícolas en México. Catálogo Histórico. Tomo I. Épocas prehispánica y colonial (9581822). México: Fondo de Cultura Económica, Centro de Investigaciones y Estudios Superiores en Antropología Social, 2003.

GARCÍA FLORES, Raúl. "Morbilidad y vulnerabilidad en una epidemia de viruela: Nuevo Reino de León, I798". Relaciones Estudios de Historia y Sociedad XXIX(II4) (2008): 45-75.

"La epidemia de viruela en el Nuevo Reino de León: una interpretación desde la perspectiva socio-racial". En El impacto demográfico de la viruela en México de la época colonial al siglo XX. La viruela antes de la introducción de la vacuna. Vol. I, ed. Chantal Cramaussel. México: El Colegio de Michoacán, 20 oro.

GONZÁLEZ FLORES, José Gustavo. Mestizaje de papel. Dinámica demográfica y familias de calidad múltiple en Taximaroa (1667-1826). Zamora: El Colegio de Michoacán, Universidad Autónoma de Coahuila, 2016.

Relaciones Estudios de Historia y Sociedad, vol. XL, núm 157, 2019 
HASKETT, Robert. Indigenous Rulers. An Ethnohistory of Town Government in Colonial Cuernavaca. Albuquerque: University of New Mexico Press, I999.

HUMBOLDT, Alejandro. Ensayo político sobre el reino de la Nueva España. Sepan cuantos, 39. México: Editorial Porrúa, I99I.

McCAA, Robert. "Inoculation: an Easy Mean of Protecting People or Propaging Smallpox? Spain and Chiapas, I779-I80o". Boletín Mexicano de Historia y Filosofía de la Medicina, vol. 2 (nueva época, septiembre ig88).

MACHUCA, Laura. "La viruela de I795-I797 en Tehuantepec, Oaxaca". En El impacto demográfico de la viruela en México de la época colonial al siglo XX. Vol. I, ed. Chantal Cramaussel, 59-70. México: El Colegio de Michoacán, 20 o.

MARTIN, Cheryle E. Rural Society in Colonial Morelos. Albuquerque: University of New Mexico, 1985 .

"Historia social del Morelos colonial". En Morelos cinco siglos de historia regional, México, Centro de Estudios Históricos del Agrarismo en México, coord. Horacio Crespo, 95-I40. México: Universidad Autónoma del Estado de Morelos, r984.

MOLINA DEL VILLAR, América. La Nueva España y el matlazahuatl 1736-1739. Colección Historias. México: Ciesas, El Colegio de Michoacán, 200 .

"Tributos y calamidades en el centro de la Nueva España, I727-I762. Los límites del impuesto justo", Historia Mexicana LIV:I(213) (julio-septiembre 2004): 15-57.

Diversidad socioétnica y familias entre las calamidades y crisis del siglo XVIII. Población en pueblos, haciendas y ranchos en doce parroquias del centro novohispano (México: Publicaciones de la Casa Chata, Ciesas, 2009).

"Demografía, salud y enfermedad, siglos XVII y XVIII con énfasis en las zonas del actual estado de Morelos". En La sociedad colonial, 1610-178o en Historia de Morelos. Tierra, gente, tiempos del Sur, coord. Brígida Von Mentz, dir. Horacio Crespo, 37-62. México: Edición de Homenaje al Bicentenario de la Independencia de México y al Centenario de la Revolución Mexicana, H. Congreso del Estado de Morelos, L Legislatura, Navarro Editores, 2009.

"La población y los conflictos por tierras y aguas en el oriente de Morelos, I700-I768". En La sociedad colonial, 1610-1780 en Historia de Morelos. Tierra, gente, tiempos del Sur, coord. Brígida Von Mentz, dir. Horacio Crespo, 34I-362. México: Edición de Homenaje al Bicentenario de la Independencia de México y al Centenario de la Revolución Mexicana, H. Congreso del Estado de Morelos, L Legislatura, Navarro Editores, 2009.

OLIVER SÁNCHEZ, Lilia V. "La Real Expedición Filantrópica de la Vacuna y la Junta Central de Vacunación en Guadalajara”. En Convergencias y divergencias: México y Perú, siglos XVI-XIX, 
coord. Lilia V. Oliver Sánchez, 205-23ı. México: Universidad de Guadalajara, El Colegio de Michoacán, 2006.

OUWENEEL, Arij. Ciclos interrumpidos. Ensayos sobre historia rural mexicana, siglos XVIII y XIX. México: El Colegio Mexiquense, 1998.

PARDO HERNÁNDEZ, Claudia Patricia. "La primera expedición de la vacuna de Balmis en la ciudad de México, I804". En El miedo a morir. Endemias, epidemias y pandemias en México: análisis de larga duración, ed. América Molina del Villar, Lourdes Márquez Morfín y Claudia Patricia Pardo Hernández, 451-462. México: Ciesas, Instituto de Investigaciones Dr. José María Luis Mora, Benemérita Universidad Autónoma de Puebla, CONACYT, 2013.

PESCADOR, Juan Javier. De bautizados a fieles difuntos. Familias y mentalidades en una parroquia urbana: Santa Catarina de México, 1568-1820. México: El Colegio de México, 1996.

RAMÍREZ MARTÍN, Susana María. La salud del Imperio. La Real Expedición Filantrópica de la Vacuna. Madrid: Fundación Jorge Juan, 2002.

"Fuentes bibliográficas para el estudio de la inoculación y la vacunación en la Nueva España". En El impacto demográfico de la viruela en México de la época colonial al siglo XX. La viruela antes de la introducción de la vacuna. Vol. I, ed. Chantal Cramaussel, I23-158. México: El Colegio de Michoacán, 2010.

RODRÍGUEZ DE ROMO, Ana Cecilia. "Inoculación en la epidemia de viruela de i797 en la ciudad de México: ¿Mito o solución real? Revista electrónica, Antilia Revista Española de las Ciencias de la Naturaleza y de la Tecnología, vol. III (1997).

SÁNCHEZ SANTIRÓ, Ernest. Azúcar y poder. Estructura socioeconómica de las alcaldías mayores de Cuernavaca y Cuautla Amilpas, 1730-1821. México: Universidad Autónoma de Morelos, Editorial Praxis, 200I.

SEDANO, Francisco. Noticias de México: crónicas de los siglos XVI al XVIII. Colección Metropolitana, 34-35. 3 vols. Prólogo Joaquín Fernández de Córdoba. México: Departamento del Distrito Federal, Secretaría de Obras y Servicios, 1974.

SCHIFTER ACEVES, Liliana, Patricia ACEVES PASTRANA y Alba Dolores MORALES COSME. "Minería e Inquisición en la Nueva España del siglo XVIII; el caso Morel". Revista de la Sociedad Química de México 46(2) (abril-junio 2002).

THOMPSON, Angela. "To save the Children: Smallpox, Inoculation, Vaccination and Public Health in Guanajuato, Mexico, I797-I840". The Americas, vol. 49 (abril I993): 431-455.

TREJO MORENO, Jessica. "La epidemia de viruela de 1797 en El Sagrario de la ciudad de México, vista a través de los registros parroquiales de defunción”. Tesis de Maestría de Historia 
Moderna y Contemporánea. México: Instituto de Investigaciones Dr. José María Luis Mora, 2016.

VALDÉS AGUILAR, Rafael. "La viruela desde el punto de vista médico". En El impacto demográfico de la viruela en México de la época colonial al siglo XX. La viruela antes de la introducción de la vacuna. Vol. I, ed. Chantal Cramaussel, 29-35. Zamora: El Colegio de Michoacán, 20 o.

VON MENTZ, Brígida. Trabajo, sujeción y libertad en el centro de la Nueva España. Esclavos, aprendices, campesinos y operarios manufactureros, siglos XVI al XVIII. México: Miguel Ángel Porrúa, Ciesas, I999.

WIDMER SENNHAUSSER. "Política sanitaria y lucha social en tiempos de viruelas: Corona, comercio y comunidades indígenas en Tehuantepec, I795-I796". Relaciones Estudios de Historia y Sociedad (44) (1990): 33-74.

\section{Notas}

I La viruela es producida por el virus variola y es una enfermedad infecciosa que se transmite de persona a persona en estrecho contacto por medio de la inhalación de pequeñas gotas emanadas de las vías respiratorias, las cuales contienen virus. Otra vía de contagio son las lesiones cutáneas en descamación, así como por contacto directo con fluidos corporales infectados u objetos (sábanas, cobijas, fundas o ropa). Los seres humanos son los únicos vectores transmisores del contagio y no por medio de animales o insectos (Rafael Valdés Aguilar, "La viruela desde el punto de vista médico", en El impacto demográfico de la viruela en México de la época colonial al siglo $X X$. La viruela antes de la introducción de la vacuna, vol. I, ed. Chantal Cramaussel, 269 (Zamora: El Colegio de Michoacán, 20Io); David Carbajal López, "Las epidemias de viruela en Bolaños, 1762-1840", Relaciones Estudios de Historia y Sociedad XXIX(II4) (2008): 2I-43.

2 Valdés Aguilar, "La viruela", 33-35.

3 Lilia V. Oliver Sánchez, "La Real Expedición Filantrópica de la Vacuna y la Junta Central de Vacunación en Guadalajara", en Convergencias y divergencias: México y Perú, siglos XVI-XIX, coord. Lilia V. Oliver Sánchez (México: Universidad de Guadalajara, El Colegio de Michoacán, 2006); Susana María Ramírez Martín, La salud del Imperio. La Real Expedición Filantrópica de la Vacuna (Madrid: Fundación Jorge Juan, 2002); Valdés Aguilar, "La viruela", 33-34.

4 El método aceptado en España y en sus posesiones, entre ellas, la Nueva España consistía en extraer una pequeña cantidad de líquido de las ámpulas de los enfermos y con una aguja o lanceta se introducía el líquido de las ámpulas en el dedo índice y pulgar.Jessica Trejo Moreno, "La epidemia de viruela de I797 en El Sagrario de la ciudad de México, vista a través de los registros parroquiales de defunción" (Tesis de maestría de Historia Moderna y Contemporánea, Instituto de Investigaciones Dr. José María Luis Mora, 20i6), 66-67. Sobre la labor científica de Morel en la Nueva España, véase: Liliana Schifter Aceves, Patricia Aceves Pastrana y Alba Dolores 
Morales Cosme, "Minería e Inquisición en la Nueva España del siglo XVIII; el caso Morel", Revista de la Sociedad Química de México_46(2) (abril-junio 2002).

5 Donald Cooper, Las epidemias en la ciudad de México, 1761-1813, Colección Salud y Seguridad Social. Serie Historia (México: Instituto Mexicano del Seguro Social, I980), 79-94. Sobre las campañas de variolización y vacunación en los siglos XIX y XX, véase: Claudia Agostoni, Médicos, campañas y vacunas. La viruela y la cultura de su prevención en México, 187o1950 (México: Universidad Nacional Autónoma de México, Instituto de Investigaciones Dr. José María Luis Mora, 2016); Claudia Agostoni "Smallpox eradication in Mexico", Latin American History, Oxford Research Encyclopedia (Oxford: Oxford University Press, 2016), I-25.

6 Sobre la controversia que suscitaba la inoculación, véase Robert McCaa, "Inoculation: an Easy Mean of Protecting People or Propaging Smallpox? Spain and Chiapas, I779-I80o", Boletin Mexicano de Historia y Filosofía de la Medicina, vol. 2 (nueva época, septiembre ig88). Este autor señala que la inoculación fue promovida por las autoridades virreinales durante el brote de viruela de I779-I780. Más tarde en I794 y I798 en Chiapas se practicaron alrededor de 90 inoculaciones en unos cuantos meses.

7 Biblioteca Nacional de la Universidad Nacional Autónoma de México (BNUNAM), Fondo Reservado, Sala Mexicana, "Instruido el excmo virrey de este reyno del estado actual de epidemia, ha calificado del todo necesario. Se tiene puntual razón del número de enfermos y muertos, I797. Junta Principal. Sociedad parcial de caridad. Manzana número del cuartel mayor". (RFO 082.I GUE 497). Sobre la reticencia de algunos médicos a la inoculación y las prácticas de aislamiento de los enfermos, véase Luz María Espinosa Cortes y Raúl Miranda Ocampo, "La epidemia de viruela de I796-I798. De Teotitlán del Valle, Oaxaca a la Ciudad de México", en El impacto demográfico de la viruela en México de la época colonial al siglo XX, vol. I, ed. Chantal Cramaussel, 76-92 (Zamora: El Colegio de Michoacán, 2oro); Neibeth Camacho Alberto, "Guanajuato y Valladolid de Michoacán durante la epidemia de viruela de 1797-I798", en El impacto demográfico de la viruela en México de la época colonial al siglo XX, ed. Chantal Cramaussel, 93-IO4 (México: El Colegio de Michoacán, 20I0), En España el padre Benito Jerónimo Feijóo fue de las primeras personas en promover la inoculación y su obra se difundió ampliamente en la Nueva España. Camacho, "Guanajuato", 95.

8 Un ejemplo de este tipo de manuales es el de Joseph Amar, "Instrucción curativa de las viruelas dispuesta para los facultativos y acomodada para todos", Madrid, I774. BNUNAM, Fondo Reservado (RFO 93-4955I).

9 "México Real Protomedicato. Método claro, sencillo y fácil qué para practicar la inoculación de viruelas, México. s.n. I797".BNUNAM, Fondo Reservado, Sala Mexicana (RFO. o82.I. GUE. 500).

Io La referencia sobre el brote de viruela de i79o procede de una iniciativa del virrey conde de Revillagigedo para impedir la propagación de la epidemia a Veracruz. Archivo General de la Nación (AGN), Reales Cédulas, v. I46, e. 215, f. 40r. En 1796 en sesión de cabildo de la ciudad de 
Puebla se informaba que llegaron a las costas enfermos de viruela procedentes de Perú. La epidemia se había propagado a Oaxaca, Veracruz y Acapulco. Se determinó establecer una cuarentena en la ciudad para frenar el contagio. Archivo del Ayuntamiento de Puebla (AAP), Actas de cabildo. Sesión de cabildo del 22 de julio de i796, v. 65, f. I43, documento citado en Virginia García Acosta et al.,Desastres agrícolas en México. Catálogo Histórico. Tomo I. Épocas prehispánica y colonial (958-1822) (México: Fondo de Cultura Económica, Centro de Investigaciones y Estudios Superiores en Antropología Social, 2003), 385 y 407.

I Raúl García Flores, "Morbilidad y vulnerabilidad en una epidemia de viruela: Nuevo Reino de León, I798", Relaciones Estudios de Historia y SociedadXXIX(II4) (2008): 45-75. Sobre el impacto de la viruela en Oaxaca, Laura Machuca, "La viruela de 1795 -I797 en Tehuantepec, Oaxaca", en El impacto demográfico de la viruela en México de la época colonial al siglo XX, vol. I, ed. Chantal Cramaussel (Zamora: El Colegio de Michoacán, 20Io), 59-70. Un balance en torno a los estudios de la inoculación y vacunación en la Nueva España en Susana María Ramírez Martín. "Fuentes bibliográficas para el estudio de la inoculación y la vacunación en la Nueva España". en El impacto demográfico de la viruela en México de la época colonial al siglo XX. La viruela antes de la introducción de la vacuna, vol. I, ed. Chantal Cramaussel, I23-I37 (Zamora: El Colegio de Michoacán, 20Io). Sobre esta misma autora véase: La salud del Imperio. En I803 se emprendió la vacunación en la Ciudad de México, donde el virrey se enfrentó directamente con Balmis, encomendado por el Rey Carlos IV en la Real Expedición de la Vacuna (Claudia Patricia Pardo Hernández, "La primera expedición de la vacuna de Balmis en la ciudad de Méxixo, i804", en El miedo a morir. Endemias, epidemias y pandemias en México: análisis de larga duración ed. América Molina del Villar, Lourdes Márquez Morfín y Claudia Patricia Pardo Hernández, 45I-462 (México: Ciesas, Instituto de Investigaciones Dr. José María Luis Mora, Benemérita Universidad Autónoma de Puebla, CONACYT, 20iz).

I2 Machuca, "La viruela", 59-70.

I3 El estudio de Canales sobre el valle de Toluca y las epidemias de viruela que azotaron la zona entre 1690 y 1833 es revelador al mostrar el impacto de los brotes de la enfermedad separando a los párvulos y adultos, así como por grupos socioétnicos. Siguiendo esta propuesta, nos interesa analizar el impacto de la viruela de 1797 por grupos de edad y calidad. Pedro Canales Guerrero, "Historia natural y cultural de la viruela y otras enfermedades infecciosas. Epidemias y endemias en el valle de Toluca, I690-I833", en El impacto demográfico de la viruela en México de la época colonial al siglo XX, vol. III, ed. Chantal Cramaussel y David Carbajal López, 4I-62 (Zamora: El Colegio de Michoacán, 2010).

I4 "Certificación del médico Rafael Atenza, médico, cirujano con licencia del Real Protomedicato de México. 3 de octubre de $1797 ”$.

I5 "Padrón general del partido de Jonacatepec de todos los sujetos que han muerto en la presente epidemia de viruelas y de los que la han padecido, enteramente restablecidos con distinción de pueblos, nombres y edades. Año de I797". AGN, Hospital de Jesús, leg. 265, número io, 82 fs.; "Oficio emitido por el virrey Branciforte al Subdelegado de Cuernavaca de noticias del número 
de contagiados de viruelas que haya en los pueblos y de los hayan fallecido de dicha enfermedad. I8 de septiembre de I797". AGN. Hospital de Jesús, leg. 265, exp. 22,28 fs.

16 "Padrón general de toda la feligresía de Jonacatepec de españoles, castas e indios de pueblo y laboríos de haciendas y ranchos. 1797". Archivo Histórico del Arzobispado de México (AHAM). fondo Episcopal, sección Secretaría arzobispal, caja I4 CL, exp. 4. 50 fs. Agradezco a Marco Iturbe y Berenise Bravo haber despejado mi duda y transmitirme mucho de su valioso conocimiento sobre las características y fecha de elaboración del "Padrón de I797".

17 "Informe de Antonio de la Banda y Garcés, subdelegado de Cuautla Amilpas. 22 de septiembre de 1797 ”. AGN. Hospital de Jesús, leg. 265, exp. 22, 23 fs.

I8 Sobre el desarrollo histórico de estas zonas, véanse los trabajos de Cheryle E. Martin, Rural Society in Colonial Morelos (Albuquerque: University of New Mexico, 1985)y Ernest Sánchez Santiró, Azúcar y poder. Estructura socioeconómica de las alcaldías mayores de Cuernavaca y Cuautla Amilpas, 1730-1821 (México: Universidad Autónoma de Morelos, Editorial Praxis, 200I).

19 América Molina del Villar, Diversidad socioétnica y familias entre las calamidades y crisis del siglo XVIII. Población en pueblos, haciendas y ranchos en doce parroquias del centro novohispano (México: Publicaciones de la Casa Chata, Ciesas, 2009), 229-234. Sobre la población y el impacto de las epidemias en esa zona durante los siglos XVII y XVIII, véase América Molina del Villar. "Demografía, salud y enfermedad, siglos XVII y XVIII con énfasis en las zonas del actual estado de Morelos", en La sociedad colonial, 1610-1780 en Historia de Morelos. Tierra, gente, tiempos del Sur . Edición de Homenaje al Bicentenario de la Independencia de México y al Centenario de la Revolución Mexicana, coord. Brígida Von Mentz, dir. por Horacio Crespo, 37-62 (México, H. Congreso del Estado de Morelos, L Legislatura, Navarro Editores, 2009).

20 La crisis de la industria azucarera fue debida a varios factores: caída en los precios del azúcar; la separación de Portugal y España, que significó la interrupción del flujo de esclavos negros a las plantaciones y los factores meteorológicos, como heladas de fines del siglo XVII. Entre r69o y i720 virtualmente todas las antiguas haciendas de los valles de Cuautla y Yautepec estaban sujetas a concursos judiciales de acreedores. No había capitales para invertir en la producción y reactivar las haciendas. Entre 1690 y 1760, la industria azucarera de Cuautla y Yautepec entró en un prolongado periodo de recesión. Cheryle E. Martin, "Historia social del Morelos colonial", en Morelos cinco siglos de historia regional, México, Centro de Estudios Históricos del Agrarismo en México, coord. Horacio Crespo, 84 (México: Universidad Autónoma del Estado de Morelos. 1984); Martin, Rural Society, 94-95.

2I Martin, Rural Society, 48, 66-70; Molina del Villar, La Nueva España y el matlazahuatl 1736-1739: Colección Historias (México: Ciesas, El Colegio de Michoacán, 200I), 273-274; Diversidad socioétnica, I34-I39, 475-486.

22 América Molina del Villar, "Tributos y calamidades en el centro de la Nueva España, I7271762. Los límites del impuesto justo", Historia Mexicana LIV:I(2I3) (julio-septiembre 2004): 44-46.

Relaciones Estudios de Historia y Sociedad, vol. XL, núm 157, 2019 
23 "Mandamiento de la real audiencia a petición del marqués del valle, para que habiendo cesado la epidemia en las jurisdicciones de Toluca, Cuernavaca y Coyoacán se proceda a cobrar los tributos a los naturales. Febrero de I763". AGN, Hospital de Jesús, vol. 9, exp. 13, I763, 6 fs.

24 Arij Ouweneel, Ciclos interrumpidos. Ensayos sobre historia rural mexicana, siglos XVIII y XIX (México: El Colegio Mexiquense, I998), 229.

25 La cifra de 1768 proviene del padrón levantado ese año y que ordenó levantar Antonio de Lorenzana. "Curato de San Agustín Jonacatepec, que se compone de ocho pueblos, iz ranchos y dos haciendas de azúcar. I768". AHAM, fondo Episcopal, sección Secretaría arzobispal, caja I4 CL, exp. $3,75 \mathrm{fs}$.

26 Sobre el uso de estereotipos y calidades en la Colonia, véase Solange Alberro y Pilar Gonzalbo, La sociedad novohispana. Estereotipos y realidades (México: El Colegio de México, 20Iz), I7-IgI. A lo largo de su vida un individuo podía ser registrado bajos distintas calidades. David Carbajal López, La población en Bolaños, 1740-1848 (México: El Colegio de Michoacán, 2008). Una discusión al respecto de las calidades y del impacto de la viruela de 1797 , en Raúl García Flores, "La epidemia de viruela en el Nuevo Reino de León: una interpretación desde la perspectiva socio-racial", en El impacto demográfico de la viruela en México de la época colonial al siglo XX. La viruela antes de la introducción de la vacuna, vol. I, ed. Chantal Cramaussel, II4-II8 (México: El Colegio de Michoacán, 20Io). Un valioso estudio sobre el significado de las calidades en los registros parroquiales y padrones en términos de adscripción y clasificación es el de José Gustavo González Flores, Mestizaje de papel. Dinámica demográfica y familias de calidad múltiple en Taximaroa (1667-1826) (Zamora: El Colegio de Michoacán, Universidad Autónoma de Coahuila, 2016).

27 Martin, Rural Society, I6I-I63; Robert Haskett, Indigenous Rulers. An Ethnohistory of Town Government in Colonial Cuernavaca (Albuquerque: University of New Mexico Press, 1999), 23-24.

28 "Padrón general de toda la feligresía de Jonacatepec de españoles, castas e indios de pueblo y laboríos de haciendas y ranchos. I797”. AHAM, fondo Episcopal, sección Secretaría arzobispal, caja I4 CL, exp. 4.

29 "Padrón general de toda la feligresía de Jonacatepec de españoles, castas e indios de pueblo y laboríos de haciendas y ranchos. I797". AHAM, fondo Episcopal, sección Secretaría arzobispal, caja I4 CL; Molina del Villar, Diversidad socioétnica, 482-483; Molina del Villar, Diversidad socioétnica, 480 .

30 García Acosta et al.._Desastres agrícolas, 405-416.

3r En relación con los estudios del impacto de este brote de viruela véase: García Flores, "Morbilidad", 45-75; Cooper, Las epidemias, II3-I96; Angela Thompson, "To save the Children: Smallpox, Inoculation, Vaccination and Public Health in Guanajuato, Mexico, I797-I840", The Americas (49) (abril I993): 43I-455; Sherbune F. Cook, "The smallpox epidemic of I797", Bulletin of the History of Medicine (7) (I939): 937-969; Ana Cecilia Rodríguez de Romo. "Inoculación en la epidemia de viruela de 1797 en la ciudad de México: ¿Mito o solución real?, Revista electrónica,

Relaciones Estudios de Historia y Sociedad, vol. XL, núm 157, 2019 210 
Antilia Revista Española de las Ciencias de la Naturaleza y de la Tecnología, vol. III (Ig97); Machuca, "La viruela", 59-70; Espinosa y Miranda, "La epidemia", 7I-92; Camacho, "Guanajuato", 93-IO4; García Flores, "La epidemia", I05-I2I; Trejo, "La epidemia". Algunos de estos textos aparecen citados en García Flores, "Morbilidad", 46, nota 3. Este autor analiza el impacto de la viruela bajo el enfoque de la Teoría Social de los Desastres, perspectiva que le permite adentrarse en las repercusiones de la epidemia y las condiciones de vulnerabilidad de la sociedad.

32 AAP, Actas de cabildo, v. 65, f. I43, en García Acosta et al., Desastres agrícolas, 407.

33 Sherbune F. Cook, "La epidemia de viruela deizg7 en México", en Ensayos sobre la historia de las epidemias en México, Enrique Florescano y Elsa Malvido (México: Instituto Mexicano del Seguro Social, I982): 298-299; García Acosta et al.,_Desastres agrícolas, 403-4I4.

34 Archivo General del Estado de Oaxaca (AGEO), Tesorería principal, 1.4, e. Ig, f. I, en García Acosta et al.,Desastres agrícolas, 399.

35 García Acosta et al., Desastres agrícolas, 402. Sobre la inoculación de Chiapas y Nueva España, véase McCaa, "Inoculation".

36 Archivo Histórico de la Biblioteca Nacional del Instituto Nacional de Antropología e Historia (AHBINAH), Michoacán, r. 7, en García Acosta et al., Desastres agrícolas, 405: Camacho, "Guanajuato", 94.

37 Alejandro Humboldt, Ensayo político sobre el reino de la Nueva España, Sepan cuantos, 39 (México: Editorial Porrúa, I9gI), 44. Cooper, Las epidemias, IIz-Ig6. Por su parte, Camacho -con base en el análisis de un informe- señala que en Valladolid se inocularon 6,80o individuos y fallecieron i7o. El elevado número de muertos en la ciudad la atribuye la autora quizá a la mala inoculación. Camacho, "Guanajuato", 97.

38 Archivo General de Indias (AGI), Indiferente General, leg. 1560, en García Acosta et al.,Desastres agrícolas, 409 .

39 Véase catálogo de fichas sobre los brotes de viruela de 1797: García Acosta et al._Desastres agrícolas, 405-4I5.

40 Chantal Cramaussel, "Introducción", en El impacto demográfico de la viruela en México de la época colonial al siglo XX. La viruela antes de la introducción de la vacuna, vol. I, ed. Chantal Cramaussel, 23 (México: El Colegio de Michoacán, 20io).

4I Camacho, "Guanajuato", 94-IO4.

42 Francisco Sedano, Noticias de México: crónicas de los siglos XVI al XVIII, Colección Metropolitana 34-35, vol. III, prólogo de Joaquín Fernández de Córdoba (México: Departamento del Distrito Federal, Secretaría de Obras y Servicios, I974), 92; Cartas de Cabildo Hispanoamericanos: Audiencia de México (siglos XVIII-XIX), vol. II, comp. Enriqueta Vila Vilar y

Relaciones Estudios de Historia y Sociedad, vol. XL, núm I57, 2019 
María Justina Sarabia Viejo, I7 (Sevilla: Consejo Superior de Investigaciones Científicas, Escuela de Estudios Hispanoamericanos, I9go); García Acosta et al., Desastres agrícolas, 4II. Sobre el impacto de la viruela de 1797 en la parroquia de El Sagrario en la Ciudad de México y la inoculación, véase: Trejo Moreno, "La epidemia"; Espinosa y Miranda, "La epidemia", 77-92.

43 AGI, Indiferente General, I560; Archivo Municipal de Saltillo (AMS), Presidencia municipal, c. 50, e. 55-58, f. 2, en García Acosta et al., Desastres agrícolas, 4IO. Cabe referir que en Teotitlán del Valle hubo una revuelta de indios que se resistieron a llevar a sus enfermos al hospital. Machuca, "La viruela", p. 64; Espinosa y Miranda, "La epidemia", 73-74.

44 Machuca, "La viruela", 59-60, nota 4. La autora se refiere al estudio de Rolf Widmer Sennhauser, quien identificó que Tehuantepec había sido la primera localidad alcanzada por la viruela hacia mayo de i795. La infección llegó desde Tonalá, Chiapas, a través de dos vías: por mar y terrestre. El estudio en cuestión apareció publicado en Relaciones Estudios de Historia y Sociedad en 1990. Widmer Sennhausser, "Política sanitaria y lucha social en tiempos de viruelas: Corona, comercio y comunidades indígenas en Tehuantepec, I795-I796", Relaciones Estudios de Historia y Sociedad (44) (1990): 33-74. Una situación similar se experimentó en Guanajuato, donde los españoles fueron menos afectados por la viruela debido en gran parte a que aceptaron ser inoculados. Camacho, "Guanajuato", I03-IO4.

45 "Padrón general del partido de Jonacatepec de todos los sujetos que han muerto en la presente epidemia de viruelas y los que la han padecido, I797”. AGN, Hospital de Jesús, leg. 265, núm. Io.

46 Carta del Br. Don Juan José Anaya, cura coadjutor y juez eclesiástico de la villa de Jonacatepec. 5 de octubre de I797". AGN, Hospital de Jesús, leg. 265, exp. 22, 23 fs.

47 "Padrón general del partido de Jonacatepec de todos los sujetos que han muerto en la presente epidemia de viruelas y de los que la han padecido, enteramente restablecidos con distinción de pueblos, nombres y edades. Año de I797". AGN, Hospital de Jesús, leg. 265, número io, 82 fs.

48 "Informe del cura coadjutor y juez eclesiástico de la villa de Jonacatepec. 5 de octubre de I797”. AGN, Hospital de Jesús, leg. 265, exp. 22.

49 Padrón general del partido de Jonacatepec de todos los sujetos que han muerto en la presente epidemia de viruelas y de los que la han padecido, enteramente restablecidos con distinción de pueblos, nombres y edades. Año de I797". AGN, Hospital de Jesús, leg. 265, número io, 82 fs.

50 "Sobre la epidemia de viruelas en Cuernavaca. Octubre de I797". AGN, Hospital de Jesús, leg. 265, exp. 22 y 23; "Padrón general del partido de Jonacatepec de todos los sujetos que han muerto en la presente epidemia de viruelas y de los que la han padecido, enteramente restablecidos con distinción de pueblos, nombres y edades. Año de I797". AGN, Hospital de Jesús, leg. 265, número IO, 82 fs.

5I Machuca, "La viruela", 68.

Relaciones Estudios de Historia y Sociedad, vol. XL, núm 157, 2019 
$5^{2}$ Thompson, "To save the Children", 43I-455; Camacho, "Guanajuato", 94-IO4.

53 "Padrón general del partido de Jonacatepec de todos los sujetos que han muerto en la presente epidemia de viruelas y de los que la han padecido, enteramente restablecidos con distinción de pueblos, nombres y edades. Año de I797”. AGN, Hospital de Jesús, leg. 265, número io, 82 fs.

54 "Carta del Br. Don Juan José Anaya, cura coadjutor y juez eclesiástico de la villa de Jonacatepec. 5 de octubre de I797" AGN, Hospital de Jesús, leg. 265, exp. 22, 23 fs.

55 "Carta de don Antonio Montoto, teniente de Jonacatepec. 25 de octubre de I797". Hospital de Jesús, leg. 265, exp. 22, 23 fs.

56 "Carta del lic. Don Antonio Buenavista, cura propio y juez eclesiástico del partido de Yecapixtla. 30 de septiembre de I797". AGN, Hospital de Jesús, leg. 265, exp. 22, 23 fs.

57 "Padrón general de toda la feligresía de Jonacatepec de españoles, castas e indios del pueblo y laboríos de haciendas y ranchos. I797". AHAM, Episcopal. Secretaría arzobispal, caja I4 CL. exp. $4,50 \mathrm{fs}$.

58 "Padrón general de toda la feligresía de Jonacatepec de españoles, castas e indios del pueblo y laboríos de haciendas y ranchos. I797”. AHAM, Episcopal. Secretaría arzobispal, caja I4 CL. exp. $4,50 \mathrm{fs}$.

59 "Padrón general de toda la feligresía de Jonacatepec de españoles, castas e indios del pueblo y laboríos de haciendas y ranchos. I797". AHAM, Episcopal. Secretaría arzobispal, caja I4 CL. exp. $4,50 \mathrm{fs}$.

6o Carbajal. "Las epidemias", 30-33. La metodología de reconstitución familiar propuesta por este autor le permite identificar familias que perdieron más de un hijo en un periodo corto. Por ejemplo, en Bolaños durante "la viruela de i780 algunas familias perdieron en un lapso de mes y medio a tres de sus miembros". Machuca, "La viruela", 64. En I798 en el valle de Toluca murieron 48 párvulos y 86 adultos españoles, mientras los indios reportaron 915 párvulos y 402 adultos. Canales, "Historia natural", 57.

6I El autor cuestiona hasta qué punto las condiciones que se presentaron en el siglo XVI, cuando la viruela devastó a las poblaciones autóctonas, se presentaron a fines del siglo XVIII. También refiere al uso de la categoría de indios para definir a un sector social. García Flores, "La epidemia", rog.

62 "Padrón general de toda la feligresía de Jonacatepec de españoles, castas e indios de pueblo y laboríos de haciendas y ranchos. I797". AHAM, fondo Episcopal, sección Secretaría arzobispal, caja I4 CL; Molina del Villar, Diversidad socioétnica, 482-483. 
63 "Padrón general del partido de Jonacatepec de todos los sujetos que han muerto en la presente epidemia de viruelas y de los que la han padecido, enteramente restablecidos con distinción de pueblos, nombres y edades. Año de I797”. AGN, Hospital de Jesús, leg. 265, núm. IO, 82 fs.

64 "Padrón general del partido de Jonacatepec de todos los sujetos que han muerto en la presente epidemia de viruelas y de los que la han padecido, enteramente restablecidos con distinción de pueblos, nombres y edades. Año de I797". AGN, Hospital de Jesús, leg. 265, núm. Io, 82 fs.

65 Véase el anexo del tomo r: Chantal Cramaussel y David Carbajal López, ed., El impacto demográfico de la viruela en México de la época colonial al siglo XX, 3 vols. (Zamora: El Colegio de Michoacán, 20I0), I39-I50. Este informe se encuentra en un documento titulado: "Sermón eucarístico por la felicidad que logró la ciudad de Durango en la epidemia de viruela del año de I798", Biblioteca Nacional de México, No. sis. 003428I7 (México: José Fernández Jauregui, I799).

66 El intendente Juan Antonio de Riaño envió a la Ciudad de México un cirujano para que se instruyera en el método de la inoculación. Riaño formó un fondo para obtener recursos y dividió la ciudad en i2 cuarteles para suministrar cuidados médicos y alimentos. Camacho, "Guanajuato", 96-97.

67 García Flores, "Morbilidad", 52-54; "La epidemia", IO5-I2I.

68 Sobre este cuestionamiento de las cifras y alcance de la inoculación, véase García Flores, "Morbilidad", 57-58; Thompson, "To save the Chidren", 438; Rodríguez, "Inoculación".

69 Espinosa y Miranda, "La epidemia", 71-92.

70 García Flores, "Morbilidad", 64-65.

\section{América Molina del Villar}

Doctora en Historia por el Centro de Estudios Históricos de El Colegio de México. Profesora Investigadora Titular C del Centro de Investigaciones y Estudios Superiores en Antropología Social (sede Ciesas-Ciudad de México). Líneas de investigación: historia demográfica, historia de las epidemias siglos XVIII-XX, historia de la familia. Últimas publicaciones: Margarita Estrada Iguíniz y América Molina del Villar, eds., Matrimonio. Intereses, afectos, conflictos. Una aproximación desde la antropología, la historia y la demografía (siglos XVIII al XXI).México: Publicaciones de la Casa Chata, 2015 (ISBN 978-607-486-320-8); Guerra, tifo y cerco sanitario en la ciudad de México, 1911-1917.México: Publicaciones de la Casa Chata, 2016 (ISBN 978-607-486379-6); "El estudio de las epidemias: enfoques sociodemográficos y culturales. Fuentes y abordajes metodológicos con énfasis en el caso Mexicano". Presente y Pasado año 2I(42) (juliodiciembre de 2016): I44-I64 (ISSN i316-i369); "Vivir en la orfandad, pobreza y hacinamiento. Los asilos constitucionalistas y las condiciones de vida y salud de los niños en la ciudad de México, I9I5-1918". Revista de Historia Moderna y Contemporánea de México (octubre-diciembre 2018): 195$242($ ISSN 2848-5004). 